\title{
Prevention and Control Strategies to Counter Zika Virus, a Special Focus on Intervention Approaches against Vector Mosquitoes-Current Updates
}

\section{OPEN ACCESS}

Edited by:

Akio Adachi,

Tokushima University, Japan

Reviewed by:

Tonya Michelle Colpitts,

Boston University, United States

Yan Li,

Experimental Therapeutics Centre

(A*STAR), Singapore

Xiaoming Sun,

Ragon Institute of MGH, MIT and

Harvard, United States

Xavier Abad,

Centre de Recerca en Sanitat Animal,

Spain

*Correspondence: Kuldeep Dhama

kdhama@rediffmail.com

Yashpal S. Malik

malikyps@gmail.com

Specialty section:

This article was submitted to

Virology,

a section of the journal

Frontiers in Microbiology

Received: 17 September 2017

Accepted: 15 January 2018

Published: 08 February 2018

Citation:

Singh RK, Dhama K, Khandia $R$

Munjal A, Karthik K, Tiwari R,

Chakraborty S, Malik YS and

Bueno-Marí R (2018) Prevention and

Control Strategies to Counter Zika Virus, a Special Focus on Intervention

Approaches against Vector

Mosquitoes-Current Updates.

Front. Microbiol. 9:87.

doi: 10.3389/fmicb.2018.00087

\author{
Raj K. Singh ${ }^{1}$, Kuldeep Dhama ${ }^{2 *}$, Rekha Khandia ${ }^{3}$, Ashok Munjal ${ }^{3}$, \\ Kumaragurubaran Karthik ${ }^{4}$, Ruchi Tiwari ${ }^{5}$, Sandip Chakraborty ${ }^{6}$, Yashpal S. Malik ${ }^{7 *}$ and \\ Rubén Bueno-Mari ${ }^{8}$
}

${ }^{1}$ ICAR-Indian Veterinary Research Institute, Izatnagar, Bareilly, India, ${ }^{2}$ Division of Pathology, ICAR-Indian Veterinary Research Institute, Izatnagar, Bareilly, India, ${ }^{3}$ Department of Biochemistry and Genetics, Barkatullah University, Bhopal, India, ${ }^{4}$ Central University Laboratory, Tamil Nadu Veterinary and Animal Sciences University, Chennai, India, ${ }^{5}$ Department of Veterinary Microbiology and Immunology, College of Veterinary Sciences, UP Pandit Deen Dayal Upadhayay Pashu Chikitsa Vigyan Vishwavidyalay Evum Go-Anusandhan Sansthan, Mathura, India, ${ }^{6}$ Department of Veterinary Microbiology, College of Veterinary Sciences and Animal Husbandry, Agartala, India, ${ }^{7}$ Division of Biological Standardization, ICAR-Indian Veterinary Research Institute, Izatnagar, Bareilly, India, ${ }^{8}$ Laboratorios Lokímica, Departamento de Investigación y Desarrollo (I+D), Valencia, Spain

Zika virus $(Z \mathrm{IKV})$ is the most recent intruder that acquired the status of global threat creating panic and frightening situation to public owing to its rapid spread, attaining higher virulence and causing complex clinical manifestations including microcephaly in newborns and Guillain Barré Syndrome. Alike other flaviviruses, the principal mode of ZIKV transmission is by mosquitoes. Advances in research have provided reliable diagnostics for detecting ZIKV infection, while several drug/therapeutic targets and vaccine candidates have been identified recently. Despite these progresses, currently there is neither any effective drug nor any vaccine available against ZIKV. Under such circumstances and to tackle the problem at large, control measures of which mosquito population control need to be strengthened following appropriate mechanical, chemical, biological and genetic control measures. Apart from this, several other known modes of ZIKV transmission which have gained importance in recent past such as intrauterine, sexual intercourse, and blood-borne spread need to be checked and kept under control by adopting appropriate precautions and utmost care during sexual intercourse, blood transfusion and organ transplantation. The virus inactivation by pasteurization, detergents, chemicals, and filtration can effectively reduce viral load in plasma-derived medicinal products. Added to this, strengthening of the surveillance and monitoring of ZIKV as well as avoiding travel to Zika infected areas would aid in keeping viral infection under check. Here, we discuss the salient advances in the prevention and control strategies to combat ZIKV with a focus on highlighting various intervention approaches against the vector mosquitoes of this viral pathogen along with presenting an overview regarding human intervention measures to counter other modes of ZIKV transmission and spread. Additionally, owing to the success of vaccines for a number of infections globally, a separate section dealing with advances in ZIKV vaccines and transmission blocking vaccines has also been included.

Keywords: Zika virus, Zika fever, mosquito management, prevention, vector control, arbovirus 


\section{INTRODUCTION}

Immediately after the Ebola virus threats, Zika virus (ZIKV) has acclaimed to be the most recent virus that is threatening the global human population. After remaining innocuous for nearly six decades (since its first report in the year 1947), its emerging status propelled to declare it as an emergency situation (Public Health Emergency of International Concern) on February 1, 2016 by the World Health Organization (WHO) (Chang et al., 2016; Chen and Hamer, 2016; Gulland, 2016; Singh et al., 2016, 2017). ZIKV, a mosquito-borne virus, belongs to the Spondweni serocomplex under the genus Flavivirus, family Flaviviridae. ZIKV causes a dengue-like febrile illness which is mild in nature, but its recent association with neurological complications (microcephaly in newborns and Guillain Barré Syndrome) has worsened the circumstances (Chitti et al., 2016; Armstrong et al., 2017). Initially the virus was restricted to Africa and Asia, but later acquired status of global threat spreading worldwide (Chang et al., 2016; Chitti et al., 2016; Singh et al., 2016; Vest, 2017; Zhang et al., 2017). The emergence of ZIKV, owing to its rapid spread, attaining higher virulence and affecting large human population with complex clinical manifestations across different countries, created panic and frightening situation to public. Additionally, lack of advanced knowledge on ZIKV and dearth of suitable prevention and treatment strategies aggravated the situation across the globe. Alike other flaviviruses, the principal mode of ZIKV transmission is by mosquitoes. Hitherto reports have confirmed that both sylvatic (between vector: hematophagous mosquito and primary host: vertebrates) and urban transmission cycles plays a crucial role in the spread of ZIKV, resulting in epidemics many a times (Diallo et al., 2014; Chan et al., 2015, 2016).

Owing to the high public health concerns associated with this virus, researchers across the globe are working high in studying in-depth the virus and the disease it causes. Appreciable focus has been made on designing and developing effective diagnostics, drugs, prophylactics, vaccines and devising appropriate prevention and control strategies (Singh et al., 2016; Munjal et al., 2017a; Rather et al., 2017). Using stateof-art technologies, quick and reliable diagnostics have been developed for detecting ZIKV infection (Singh et al., 2018), while several drug/therapeutic targets along with vaccine candidates have become known (Fernandez and Diamond, 2017; Munjal et al., 2017a,b; Sharma and Lal, 2017). Recently, viral NS2BNS3 protease was found to be an effective antiviral drug target for the treatment of ZIKV (Kang et al., 2017). Despite these advances, currently there is neither any effective treatment nor any vaccine available against ZIKV and its associated complications. Under such circumstances, adapting suitable prevention and control measures such as checking the spread and bite of the vector mosquitoes through controlling their population by means of mechanical, chemical, biological and genetic approaches, remains crucial and valuable steps to keep ZIKV infection under check (von Seidlein et al., 2017). Apart from this, several other known modes of ZIKV transmission which have gained significance in the recent past such as intrauterine, sexual intercourse, and blood-borne spread need to be checked and kept under control through following appropriate precautions and utmost care during sexual intercourse, blood transfusion and organ transplantation. The virus inactivation by pasteurization, detergents, chemicals and filtration can effectively reduce viral load in plasma-derived medicinal products. Added to this, strengthening of the surveillance and monitoring of ZIKV, enhancing biosecurity as well as avoiding travel to Zika infected areas would aid in keeping ZIKV infection under check. Apart from these effectual measures, predisposing factors including climate changes (global warming), modulation of population dynamics, rapid globalization, fast travel aids and pathogen related attributes, which are responsible for an upsurge in the incidences, outbreaks and emergence of mosquito-borne diseases especially caused by pathogens like Chikungunya, Dengue, Japanese encephalitis, West Nile, and Zika virus need adequate attention (Dhiman et al., 2010; Dhama et al., 2013; Parham et al., 2015; Gautret and Simon, 2016).

Here, we describe the salient advances in prevention and control strategies to combat ZIKV with a focus on highlighting various intervention approaches against the vector mosquitoes of this viral pathogen as well as an overview on human intervention measures needed to counter other modes of ZIKV transmission and spread. The vaccine platforms that are being intended for the development of an effective vaccine against ZIKV and other transmission blocking vaccines are also dealt herein.

\section{Modes of Transmission of ZIKV}

The well-established mode of ZIKV transmission is through mosquito bite. The most significant mosquito vector responsible for transmission of ZIKV is Aedes (Stegomyia), but Anopheles, Culex, Mansonia, and Eretmapodites can also transmit the virus (Berthet et al., 2014; Diagne et al., 2015). ZIKV was first isolated from Aedes africanus, which plays a crucial role in the ZIKV sylvatic transmission cycle. Aedes aegypti and Aedes albopictus are more significant vectors in the urban transmission cycle, as they are distributed over a wider geographical range (Gasperi et al., 2012; Chan et al., 2016). Figure 1 depicts the cycle of ZIKV transmission between infected and uninfected humans through the mosquito bites. The reservoir host-mosquito-reservoir host transmission cycle has a period of incubation that varies from 2 to 5 days in the reservoir host and 5 to 7 days in the mosquito (Al-Qahtani et al., 2016). Non-vectored transmission can occur through blood transfusion, transplacental, and sexual modes (Mead et al., 2017). Other means of virus transmission include breast feeding, saliva, or urine, however no concrete evidence exists regarding ZIKV transmission through these routes (Foy et al., 2011; Musso et al., 2014). Additional in-depth studies are warranted to find the probability of alternate mode of ZIKV transmission. Presently, these non-vector borne routes have not gained as much research attention as the mosquito-borne route. The strategies that have been adopted for Ae. aegypti eradication remain inefficient as is indicated by a very high mosquito infestation index (Zanluca and dos Santos, 2016). It appears that these strategies have been clearly formulated as a public health response to a ZIKV epidemic. These strategies 


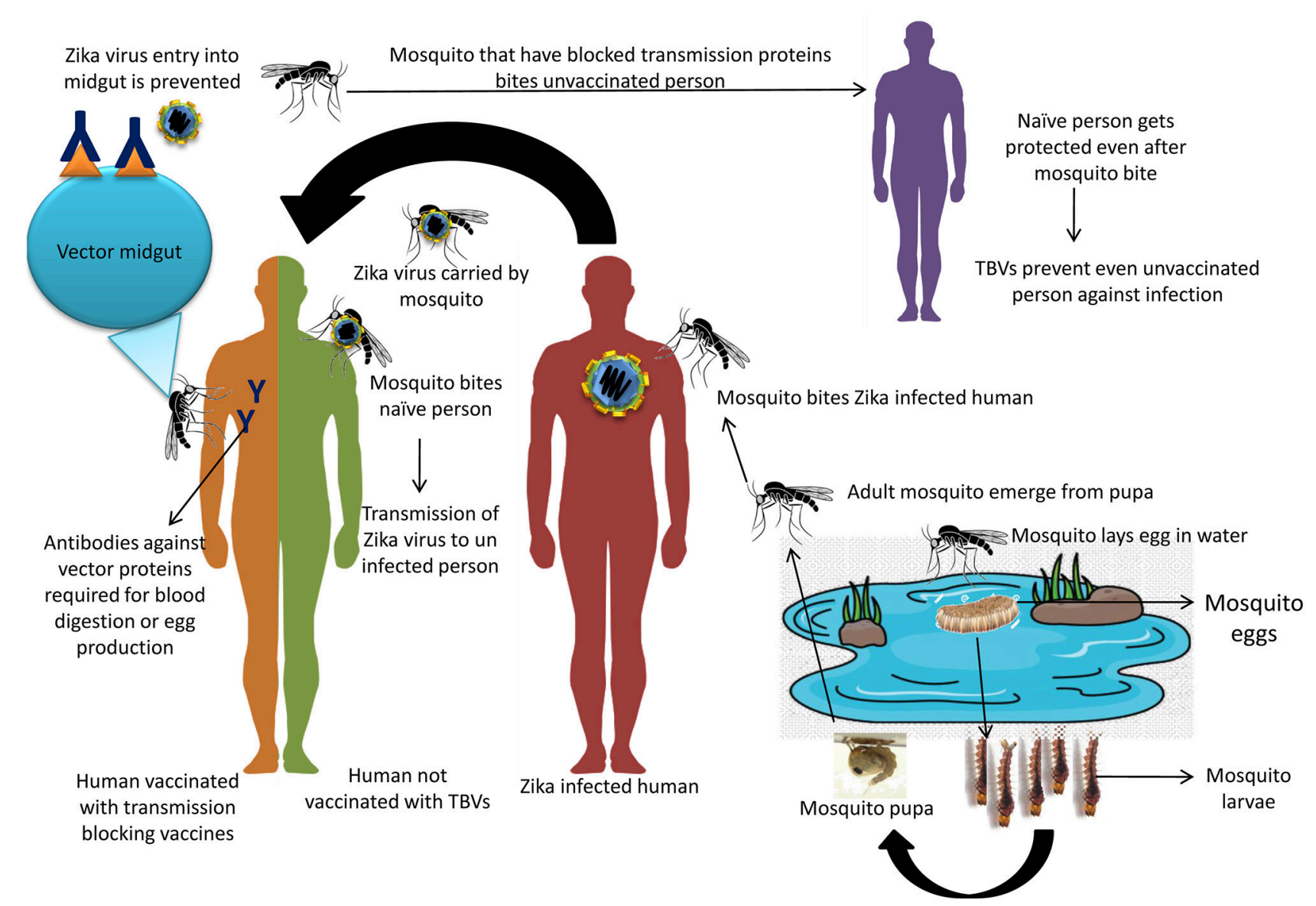

FIGURE 1 | Modes of ZIKV transmission between infected and uninfected person through mosquito bite and possible mode of TBVs in prevention and control of ZIKV infection.

involve intercepting the life cycle (enzootic) to halt the growth of the vector in its native environment, reducing exposure of susceptible subjects to the vector, limiting the source of the vector to the urban population, eliminating the vector, and preventing infected mosquitoes from biting humans (Weaver, 2013).

\section{PREVENTION AND CONTROL STRATEGIES COUNTERING THE ZIKA VIRUS}

Prevention is always considered better than cure. Strategies to prevent ZIKV infection include mechanical, chemical, or biological control measures to prevent mosquitoes from spreading. Correspondingly, personal preventive measures are parallelly important.

\section{Prevention and Control of Mosquitoes}

Since, the prime mode of ZIKV transmission is through mosquitoes, it is essential to concentrate on the methods that can control mosquitoes, so that its spread can be kept at bay. Lately, several preventive and control measures are reported to check the ZIKV spread (von Seidlein et al., 2017). These include mosquito population control through preventing or inhibiting breeding (Hajra et al., 2016), and protecting the community from the infected Aedes vector population. For effective mosquito control, mechanical, chemical, and biological measures should be employed (Araújo et al., 2015; Malone et al., 2016). In this direction, the herbal remedies and biological control strategies, such as the release of sterile male Aedes have been employed (Singh et al., 2016). It is crucial that public health authorities must intervene now because the virus has spread over larger areas rather than concentrating in a single geographic location (Aubry et al., 2015).

\section{Mechanical Control Measures}

Mechanical control measures are the age old techniques, which have been adopted and practiced out in several countries; since these are easy and cost-effective methods for the control of mosquito population. Mechanical control measures include the removal of all objects storing unwanted water, as these become sites for mosquitoes breeding. Streets should be properly cleaned and buildings and housing units must be properly maintained. Personal and community hygiene is also a major part of this 
technique, which can reduce mosquito breeding places. The use of mosquito nets on windows and mosquito-proof water storage options should be encouraged (Sikka et al., 2016). Ovitraps are cheaper and maintenance free, which can be used to reduce mosquito population (Barrera et al., 2014). Major urban ZIKA vectors, namely Ae. aegypti and Ae. albopictus show a strong degree of domiciliary behavior and are found breeding in different types of artificial containers placed in private areas. Therefore, citizen awareness is essential to avoid potential breeding sites in domiciles and this mechanical control measure can be easily applied even by a non-qualified personal. Following a better hygienic life style, mosquito bites / breeding sites can be eliminated and thereby major threats of vector borne diseases like ZIKV can be prevented.

\section{Chemical Control Measures}

Chemical treatment includes the use of pyrethroids, organochloride, and organophosphorus, which primarily act on the nervous system of the vector (van den Berg et al., 2012). Imidacloprid, thiacloprid, and thiamethoxam have larvicidal and adulticidal efficacies in different mosquito species. The use of fogging with insecticides is adopted in the outdoor environment to control the vector population though this can lead to development of resistance among the vector population (Maciel-de-Freitas et al., 2014; von Seidlein et al., 2017). The development of resistance and bioaccumulation are major problems associated with the use of chemicals to control mosquitoes (Uragayala et al., 2015). Moreover, most of these chemical products have other environmental problems because of their wide range of toxic action for several organisms, such as being non-specific insecticides and negatively affecting in some cases to all arthropods or even the rest of aquatic fauna as well as mammals and birds. Consequently, although these chemicals are currently necessary to reduce adult mosquito populations in concrete epidemiological scenarios, however a deep analysis of benefits-costs balance should be addressed before implementing a large-scale use of these insecticides for mosquito control. Repellents can be used at household to prevent mosquito nuissance at home thus preventing major mosquito borne diseases like ZIKV. Recently, a study compared the efficacy of repellet sprays with devices that repell mosquitoes, where N,N-Diethyl-meta-toluamide (DEET) and p-menthane-3,8diol were found better effective repellent among the 11 different mosquito repellent sprays used (Rodriguez et al., 2017). Similarly, devices with metofluthrin were found more effective in attracting mosquito among the five devices compared (Rodriguez et al., 2017). Of note, DEET and picaridin-containing insect repellents have been found safe for the pregnant women (Kline and Schutze, 2016). Permethrin treated mosquito repellent apparels are available to prevent from mosquito bites (Richards et al., 2017). To note further, unwashed clothes and those which were not exposed to light showed highest repelling activity (Richards et al., 2017).

Insect growth regulators (IGRs) are promising alternatives with high degrees of insecticidal efficacy and environmentally safe compared to conventional chemical larvicides (Mulla et al., 1986; World Health Organization, 1997). Analogs of juvenile hormone like methoprene or pyriproxyfen, and chitin synthesis inhibitors such as diflubenzuron and triflumuron are some examples of efficient mosquito larvicides. Some of these IGRs like pyriproxyfen are good candidates for autodisemination strategies, having positive results in recent trials conducted against ZIKV vectors (Unlu et al., 2017; von Seidlein et al., 2017). Since essential endocrine pathways for the activity of pyriproxyfen are lacking in human, there is no negative effect in human population (Hirano et al., 1998). Notingly, the judictive usage of appropriate chemicals could prevent the growing mosquito population and spread of several diseases inclduing ZIKV infection.

\section{Biological Control Measures}

Alternative to the use of chemicals, several biological measures against mosquitoes have been exploited with few having high efficacy to combat mosquito population at large. Numerous biological measures, such as the use of bacteria, fungi, plants, and fish employed to control the growth and propagation of the mosquito population.

\section{Biocontrol measures using bacteria}

A bacterium that can infect mosquitoes could be exploited to manipulate mosquito population. In 1976, the bacteria Bacillus thuringiensis subsp. israelensis (Bti) was isolated and found to be toxic to mosquito larvae (Goldberg and Margalit, 1977), and since the early 1980s, Bti-based insecticides have been available commercially. Bti is a target-specific insecticide that at the time of sporulation produces a highly specific delta-endotoxin, which is only toxic to larvae of mosquitoes, black flies and closely related flies upon ingestion. Bacillus sphaericus (Bs) is another bacterium commonly used against mosquitoes with similar characteristics to Bti. However, Bs that has been shown to persist longer than Bti in polluted habitats and, under certain circumstances, can recycle in larval cadavers increasing the residuality (Lacey, 2007). Both types of bacterial biolarvicides have become the predominant non-chemical means employed in recent years for control of mosquito larvae at several regions of USA and many countries of Europe.

Another strategy employed is the use of intracellular bacteria Wolbachia, which has been used as a biopesticide to control mosquito population. The method of use of Wolbachia for suppression of mosquito population is called as Incompatible Insect Technique (Lees et al., 2015). The intracellular, maternal transferring bacterium Wolbachia can effectively reduce vector competence for ZIKV by reducing the lifespan of the female mosquito and inducing cytoplasmic incompatibility (Nguyen et al., 2015; Aliota et al., 2016). Though Wolbachia is found in several nematodes and arthropods they do not naturally occur in Ae. aegypti (Werren, 1997; Walker et al., 2011). When Wolbachia infected female mosquito mates with normal or Wolbachia infected male, offspring's with Wolbachia are produced. Similarly, when normal female mates with Wolbachia infected male, offspring's will not be produced owing to cytoplasmic incompatibility (Caragata et al., 2016). Wolbachiainfected mosquitoes were released in areas of Rio de Janeiro during recent ZIKV episodes to control mosquitoes and 
virus transmission (Callaway, 2016). Ae. aegypti infected with the Wolbachia, a Drosophila strain, efficiently blocks the transmission of ZIKV. The male mosquitoes once infected with Wolbachia prior to mating results in laying of sterile eggs (Dutra et al., 2015). Alpha-proteobacteria of the genus Asaia are acetic acid symbionts present in the female gut and the male reproductive tract of adult Ae. aegypti and anopheline mosquitoes. The bacteria are both horizontally and vertically transmitted and can be engineered to reduce the lifespan of the insect. Wolbachia sp. and Asaia sp. may negatively interact and are mutually exclusive (Favia et al., 2008; Lambrechts et al., 2015; Rossi et al., 2015). Bacteria are easy to grow, maintain and manipulate in order to harbor desirable qualities; and on appropriate culture media, bulk amounts may be generated with relative ease. Thus, utilization of the predator-prey approach can help to avert the transmission of ZIKV.

\section{Biocontrol measures using fungi}

The fungi, Metarhizium anisopliae and Beauveria bassiana, can also be used as biocontrol measures against mosquitoes. Their conidia can adhere to and germinate on the cuticle and penetrate into the body of Aedes mosquitoes. The hyphae thicken and disrupt the integument and hemocoel. This is followed by invasion of other internal organs and death of the host, which leads to further dispersal of conidia to infect other insects (Darbro and Thomas, 2009; Tiago et al., 2014). The fungus, Beauveria bassiana, has been approved by the United States Environmental Protection Agency to be used as a biological mosquito control measure. Jaber et al. (2016) isolated 42 fungal strains from 17 different decaying arthropod cadavers. Out of theses 42 isolates, 8 isolates exhibited high pathogenicity in a Drosophila melanogaster model. Only one strain, Aspergillus nomius, exhibited properties similar to Beauveria bassiana and killed $100 \%$ of the Aedes adults. Hence, it was suggested that A. nomius can also be used for the control of mosquitoes. $B$. bassiana had already shown better adulticidal activity and hence can be used in the mosquito traps for an effective control of the vectors (Snetselaar et al., 2014). Insect cuticle is the major barrier that primarily prevents the entry of pathogens; but the cuticle is usually breached by the germinating fungal spores, and in real terms, the fungus seems to be the true entomopathogen, however, to reach to any conclusion, it is required to be tested in the natural infection settings. This may be obtained by simply spraying the fungal spores and then evaluating the efficacy of fungus to be used as a biocontrol measure.

\section{Biocontrol measures using mosquitoes against mosquitoes}

Certain mosquitoes predates other mosquito larvae and even adults, hence these species can be utilized to control Aedes sp. mosquitoes that spread ZIKV. Toxorhynchites splendens is a species of mosquito that does not feed on blood. Its larvae feed on the larvae of other mosquito species, while the adults feed on honeydew, fruit, and nectar (Benelli et al., 2016a). In a small-scale study, Mesocyclops aspericornis and Toxorhynchites speciosus together were found to contain the Aedes sp. population and together they formed a compatible predator pair, with one not affecting the survival of the other (Brown et al.,
1996). Toxorhynchites adults are often called elephant mosquitoes because they are larger than Aedes mosquitoes. They are considered harmless to humans due to their non-hematophagous nature. Berberis tinctoria fabricated silver nanoparticles exhibit acute toxicity toward Ae. albopictus, while sparing the mosquito predators T. splendens and M. thermocyclopoides (Kumar et al., 2016). Hence, such green nanoparticles may play an effective role as eco-friendly nanopesticides. However, the effects on other aquatic fauna need to be evaluated. Zuharah et al. (2015) showed a prey preference of T. speciosus toward Ae. aegypti, when Ae. aegypti, Ae. albopictus, and An. sinensis were present in the same container (Zuharah et al., 2015). Mosquito predators constitute beneficial strategy in-situ and after introduction in the water body, these predators provide a sustainable system for mosquito clearance and hence mosquito predators can be used for control of Aedes sp. mosquitoes thereby preventing the spread of ZIKV. Various mosquito vector control strategies have been represented in Figure 2.

\section{Biocontrol measure using copepods}

Mesocyclops and Macrocyclops are the major Copepods used as mosquito biocontrol measure. These feed on first instar larvae. Mesocyclops thermocyclopoides is a predator of the Ae. aegypti mosquito and its predatory efficiency increases by $8.7 \%$ in the presence of Solanum xanthocarpum fruit extract (Mahesh Kumar et al., 2012). Simple protocols have been developed for breeding Copepod species for maintenance and mass propagation prior to their release as biocontrol measures (Suarez et al., 1992).

Electron microscopy of predation behavior of Mesocyclops sp. demonstrated that the attack occurs first on the anal segment, followed by the siphon and the abdomen. The head segment is the least preferred site of attack (Schaper and Hernández-Chavarría, 2006). Treatment with Mesocyclops, reduced the incidence of dengue virus (DENV) outbreak in Vietnam in a program during 2002 and 2003 (Vu et al., 2005). These results sustained for several years, with an abundance of Mesocyclops and reduced numbers of Ae. aegypti larvae (Kay et al., 2010). Predation efficacy of $M$. formosanus is higher for larvae at the first and second instars than the third and fourth instars. Several other predatory copepods include Cyclops vernalis, Mesocyclops aspericornis, Mesocyclops edax, Mesocyclops guangxiensis, Mesocyclops longisetus (Mahesh Kumar et al., 2012; Anbu et al., 2016; Kumar et al., 2016). Practically, rearing a copepod is economic and easy as it requires little assistance for maintaining the colonies. Hence, copepods like Mesocyclops can be used for the control of mosquitoes spreading ZIKV.

\section{Biocontrol measures using plants}

Many plant-derived products are being tested for their effectiveness against mosquitoes. For lavicidal purpose there has been employment of several plants to synthesize nanomosquitocides. A methanolic seed extract from the Brazilian plant, Myracrodruon urundeuva Fr. Allemao, was found to be highly toxic to Ae. aegypti larvae at the concentration of $1,000 \mu \mathrm{g} / \mathrm{ml}$. As, the plant extract also showed toxic effects to non-mosquito predator, Artemia salina ( $\mathrm{LC}_{50}$ of $1,500 \mathrm{ppm}$ ), due care should be provided when considering this plant extract 


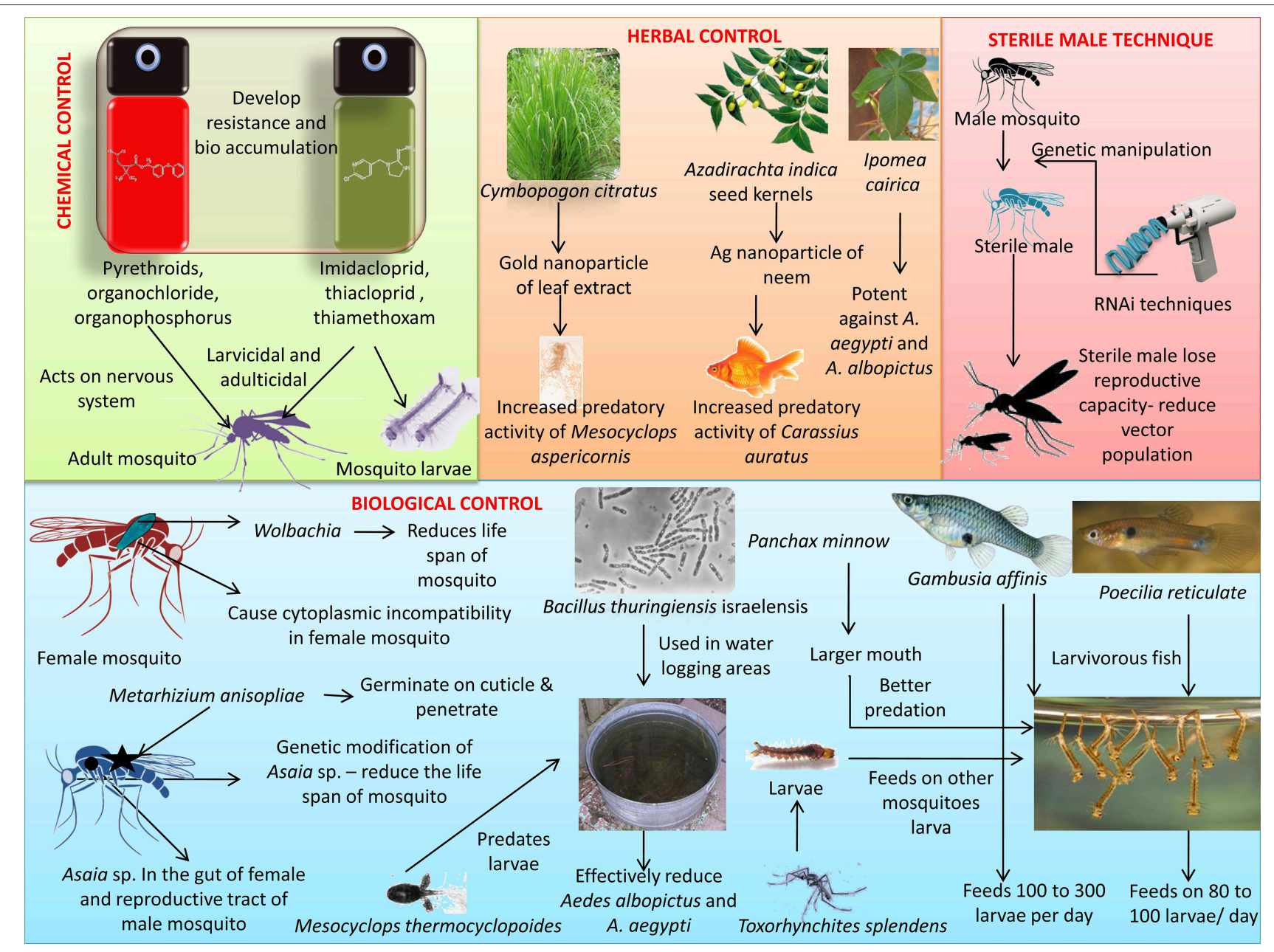

FIGURE 2 | Different mosquito vector control strategies for preventing transmission of Zika virus. Control methods include chemical (use of repellents), biological (use of bacteria, fish, etc.), herbal and sterile male techniques.

in the mosquito control program (Souza et al., 2011). Reegan et al. (2015) tested extracts from five medicinal plants, Aegle marmelos (Linn.), Limonia acidissima (Linn.), Sphaeranthus indicus (Linn.), Sphaeranthus amaranthoides (Burm. f), and Chromolaena odorata (Linn.), for ovicidal activity against Culex quinquefasciatus and Ae. Aegypti. A hexane extract of L. acidissima gave the highest ovicidal activity (79.2 and $60 \%$ against $C x$. quinquefasciatus and Ae. Aegypti, respectively) at the concentration of $500 \mathrm{ppm}$ and was found to be effective for use in an integrated mosquito management program (Reegan et al., 2015). Testing of the botanical insecticides extracted from other plants, including Apium graveolens (the seed oil is a good repellent against Aedes mosquitoes), Callistemon rigidus, and Persea americana revealed $A$. graveolens to have larvicidal activity against Ae aegypti ( $\mathrm{LC}_{50}$ and $\mathrm{LC}_{90}$ of 16.10 and $29.08 \mathrm{ppm}$, respectively). Hitherto reports confirm that the oil extract from this plant possess $100 \%$ repellent effect against adult mosquiotes upto 3 h (Kumar et al., 2014; Ramkumar and Karthi, 2015).

An essential oil from Syzygium lanceolatum showed larvicidal effects on Ae. aegypti (LC $\mathrm{L}_{50}$ value of $55.11 \mathrm{ppm}$ ), Ae. albopictus
( $\mathrm{LC}_{50}$ value of $\left.66.71 \mathrm{ppm}\right)$, An. stephensi ( $\mathrm{LC}_{50}$ value of $51.20 \mu \mathrm{g} / \mathrm{ml}$ ), An. subpictus ( $\mathrm{LC}_{50}$ value of $61.34 \mathrm{ppm}$ ), $C x$. quinquefasciatus ( $\mathrm{LC}_{50}$ value of $60.01 \mathrm{ppm}$ ), and $C x$. tritaeniorhynchus ( $\mathrm{LC}_{50}$ value of $72.24 \mathrm{ppm}$ ) larvae. Its toxic effect on water bugs (Anisops bouvieri and Diplonychus indicus) and fishes (Gambusia affinis and Poecilia reticulata) was found to be very low (LC50 value between 4,148 and 15,762 ppm) and hence, this can be used as an eco-friendly mosquito repellent (Benelli et al., 2016b). Essential oils from the Casuarina equisetifolia plant have been shown to have mosquitocidal effects against $A n$. gambiae and Ae. aegypti. Nineteen compounds were identified from the oil, with fatty acids being the major component. Other compounds that were identified include nhexadecanoic acid (18.67\%), cis-13-octadecanoic acid (17.83\%), tridecane (11.84\%), Undecane (10.45\%), Hentriacontane (8.91\%), Nonanal (8.62\%), and Oxirane (2.43\%). The knock down $\left(\mathrm{KDT}_{50}\right)$ potential of the essential oil was evaluated and it was found to be $40 \mathrm{~min}$ for An. Gambiae while $61 \mathrm{~min}$ for Ae. aegypti. The essential oil could also effectively kill $100 \%$ of the mosquitoes within $24 \mathrm{~h}$ (Adeosun et al., 2016). Another study 
also reported that essential oil from Origanum scabrum had effective larvicidal properties against a variety of mosquitoes, including An. stephensi (LC $\mathrm{L}_{50}$ of $\left.61.65 \mathrm{ppm}\right)$, Ae. aegypti ( $\mathrm{LC}_{50}$ of $67.13 \mathrm{ppm}$ ), Cx. quinquefasciatus ( $\mathrm{LC}_{50}$ of $72.45 \mathrm{ppm}$ ), and Cx. tritaeniorhynchus ( $\mathrm{LC}_{50}$ of $78.87 \mathrm{ppm}$ ) (Govindarajan et al., 2016a). Similarly, the essential oil also had ovicidal activity against An. stephensi, Ae. aegypti, Cx. quinquefasciatus and $C x$. tritaeniorhynchus with $\mathrm{LC}_{50}$ value of $160,200,240$, and $280 \mathrm{ppm}$, respectively. The essential oil also prevented the bite of An. stephensi, Ae. aegypti, Cx. quinquefasciatus and Cx. tritaeniorhynchus up to $210,180,150$, and $120 \mathrm{~min}$, respectively. This essential oil was found less toxic to non-mosquito predators like Anisops bouvieri, Gambusia affinis, and Diplonychus indicus with $\mathrm{LC}_{50}$ range of 4,162 to 12,425 ppm (Govindarajan et al., 2016a). Essential oils from other herbs, such as Heracleum sprengelianum, have also been studied for their larvicidal activity, revealing effectiveness against Ae. albopictus, An. subpictus, Cx. tritaeniorhynchus with $\mathrm{LC}_{50}$ value of $37.5,33.4$, and 40.9 ppm, respectively. This essential oil was found less toxic to fish A. bouvieri, D. indicus, and G. affinis (Govindarajan and Benelli, 2016). Different plant parts of Ipomoea cairica (Railway Creeper) were evaluated for larvicidal efficacy against Aedes using the World Health Organization (WHO) standard larval susceptibility test method. An acetone extract of the I. cairica leaf was found most potent against Ae. aegypti and Ae. albopictus with $\mathrm{LC}_{50}$ value of $450 \mathrm{ppm}$ (AhbiRami et al., 2014). In the tests conducted according to the WHO test procedures for larval and adult bioassays, Glycosmis pentaphylla leaf extracts exhibited larvicidal and adulticidal activities against An. stephensi, Cx. quinquefasciatus, and Ae. aegypti mosquitoes. The extracts had larvicidal activity with $0.4,266.9,58.5 \mathrm{ppm}$ corresponding to An. stephensi, Cx. quinquefasciatus, and Ae. Aegypti respectively (Ramkumar et al., 2016).

Hexanic extracts from flower of Clusia fluminensis contain clusianone, a benzophenone that can significantly inhibit survival and thus kills the larvae of Ae. aegypti at a concentration of $50 \mathrm{mg} / \mathrm{L}$ (Anholeti et al., 2015). Also, in the presence of plant-synthesized metal or carbon nanoparticles, the predatory efficiency of biological agents increases. Low quantities of gold nanoparticles, synthesized using an extract from the Cymbopogon citratus leaf, increased the predatory efficiency of the cyclopoid crustacean, Mesocyclops aspericornis, against Ae. aegypti from 56 to $77.3 \%$ (Murugan et al., 2015a). Similarly, a methanolic extract from the seaweed, Gracilaria firma, increased the predation efficacy of $M$. formosanus for Ae. aegypti (Kalimuthu et al., 2014). Hence, Mesocyclops sp. combined with proven herbal extracts can synergistically increase the predation of Aedes sp. Neem cake, a byproduct of neem oil extraction from the seed kernels of Azadirachta indica, has also been used to biosynthesize silver nanoparticles (AgNP). Such AgNP showed lesser LC $_{50}$ value of $3.969 \mathrm{ppm}$ (for larva of Ae. aegypti) and $8.308 \mathrm{ppm}$ (for pupa) as compared to neem cake having $\mathrm{LC}_{50}$ value of 106.53 (larva) and $235.36 \mathrm{ppm}$ (pupa). Treatment with these nanoparticles also increased the predation efficiency of Carassius auratus (Goldfish) (Chandramohan et al., 2016). Silver nanoparticlebased Ichnocarpus frutescens extract showed larvicidal properties against An. subpictus, Ae. albopictus, and Cx. tritaeniorhynchus, and hence, is a promising candidate for mosquito control (Govindarajan et al., 2016b). Overall, the use of herbal extracts seems to be a promising area for the elimination of mosquitoes without any problem of bio-accumulation. However, prior to their use, these extracts must be tested for any acute or chronic toxic activity against other insects or higher organisms.

\section{Biocontrol measures using fish}

The fish, Gambusia affinis, is one of the most successful biological control measures for mosquitoes, having been historically introduced in many regions of the world in the fight against malaria with notable results in terms of vector reduction. The fish has a predation rate of 100-300 larvae per day. Immediately after its use for predation of mosquitoes, this fish was found to be invasive as it not only predate mosquito larvae but also predate the native fishes and tadpoles (Mischke et al., 2016). A study conducted on 36 G. affinis fish revealed that almost 24 fish had tadpole of Hyla regilla (Pacific tree frog) in their stomach while only 20 fish had mosquito larvae. Thus, G. affinis does not specifically predate mosquito larvae; hence care should be taken while using this fish specifically for mosquito larvae predation (Goodsell and Kats, 1999). Similarly, another predatory fish Gambusia holbrooki was used for mosquito larvae control in Australia but later this fish became a nuisance as it caused the decline of native aquatic life (Wilson, 1960; Walton et al., 2012). A predatory efficacy study was conducted employing three native fish species of Australia (Pseudomugil signifer, Hypseleotris galii, and Pseudogobius sp.) and Gambusia holbrooki. Best results were obtained for $P$. signifier and $G$. holbrooki in predating the mosquito instars, but due to the concern raised over G. holbrooki, the native species $P$. signifier was recommended for the mosquito control in Australia (Griffin, 2014). Another fish used for this purpose is the guppy (Poecilia reticulata), which consumes about 80-100 mosquito larvae per day. Predatory fishes are small, highly tolerant and can survive in shallow water and water body margins where mosquito larvae breed. Through adequate education on their effectiveness, these fish may be incorporated as part of an integrated mosquito management program (Kant et al., 2013; Sarwar, 2015). Poecilia reticulata is able to tolerate higher temperatures and marshy habitats. However, Panchax minnow was found to have superior predation efficiency in deep water compared to the guppy. Although the guppy is a more efficient predator in shallow water, overall predation efficiency of Panchax minnow is greater, because its mouth is $70 \%$ larger than the mouth of a similarly sized guppy (Gupta and Banerjee, 2013). Gambusia holbrooki and P. signifier fish exhibit high predation rates of both 2 nd and 4 th instar larvae of Ae. vigilax (Griffin, 2014).

Channa gachua, an endogeneous species from Assam, India, has been shown to be a voracious carnivorous feeder. It can live in turbid water and therefore, it has a wider biocontrol application. P. sophore and T. fasciata are omnivorous fish which, in the absence of mosquito larvae, may feed upon algae and plankton (Phukon and Biswas, 2013). C. gariepinus is also an exotic fish having higher predation efficiency than Gambusia affinis, Poecilia reticulata, and Carassius auratus and it is well adapted for controlling mosquitoes in shallow water bodies and 
marshy areas. C. gariepinus has been shown to successfully control a mixed population of An. stephensi, An. subpictus Grassi, Armegeres subalbatus Coquillett, $C x$. quinquefasciatus, and $C x$. vishnui (Ghosh et al., 2005). A recent study has revealed that the combination of larvivorus fish with larvicidal chemicals gave better results when compared with the use of predatory fish alone (Anogwih et al., 2015); however, threat of disturbance of native flora and fauna remain in doubt. Hence, prior identification of native larvivorus fish and combing with larvicidal agents can prevent mosquitoes at their instar stage. Thus, there is need to cautiously select a predatory fish of native species that would not cause damage to the already existing flora and fauna.

\section{Biocontrol measures using tadpoles}

Tadpoles of frogs are found to predate larvae of different mosquito species. Tadpoles of five frog species namely Bufo, Euphlyctis, Hoplobatrachus, Polypedates, and Ramanella were studied for the predatory activity of Ae. aegypti eggs. Notably, Ae. aegypti eggs were found in the guts of all the tadpoles showing predatory activity for mosquito eggs (Bowatte et al., 2013). Consequently, a study revealed that larvivorous property of Hoplobatrachus tigerinus tadpole against Ae. aegypti increases with the use of synthesized silver nanoparticles and Artemisia vulgaris leaves (Murugan et al., 2015b). It was opined that most of the tadpoles are herbivores, which is a contraindicatory finding to the earlier fact. Further, it has been confirmed that both tadpole and mosquito larvae feed on the debris in the aquatic environment (Weterings, 2015) and even certain mosquitoes analyze the aquatic environment for the presence of tadpoles before oviposition, thus adapting to the aquatic environment for its survival (Weterings, 2015). More studies are warranted in this direction so that tadpoles which share the micro-environment with the mosquito larvae can be exploited to control mosquito population.

\section{Genetic Tailoring}

Mosquitoes are genetically tailored to transmit lethal gene to offspring that is kept under the genetic control of tetracycline gene. Hence, offspring's of the genetically tailored mosquitoes need tetracycline in water for their survival; which usually does not exist in environmental water, thus leading to death of the larvae (Specter, 2012; von Seidlein et al., 2017). Field studies in Brazil and Cayman Islands showed 85 and $80 \%$ reduction in vector population, respectively (Harris et al., 2012; Achee et al., 2015). Prior approval is also needed from suitable governing bodies before releasing these genetically modified mosquitoes into the environment (Vythilingam et al., 2016). Mosquitoes can be genetically modified, thereby resulting in the development of a mosquito population whose offspring are incapable of surviving. A reduction in the mosquito population through genetic modification will also cause a reduction in mosquito bites in humans and susceptible primates. The genetically engineered strain, Ae. aegypti OX513A, has previously been used for controlling the spread of DENV and it is expected to also be effective in controlling the spread of ZIKV (Phuc et al., 2007; Alphey and Alphey, 2014). In fact, genetically engineered Ae. aegypti mosquitoes developed by the British firm Oxitec have been approved by the FDA to combat ZIKV, with the expectation that these mosquitoes will have no significant environmental. These genetically engineered mosquitoes will be able to self-limit the mosquito population. Though the genetically modified strain, Ae. aegypti OX513A, is intended to curb mosquito vector-borne diseases, the modified mosquitoes present with undesirable traits, such as reduced life expectancy, delayed pupation, small-sized adults, and reduced performance compared to their unmodified counterparts (Bargielowski et al., 2011). The disadvantage of this method will be the cost employed for large scale engineering the mosquitoes (Vythilingam et al., 2016). Such approaches will increase the communication between the public and health practitioners as well as policymakers for potentially using genetically modified/engineered mosquitoes to combat infection caused by ZIKV (Adalja et al., 2016).

\section{Sterile Insect Technique}

Sterile insect technique (SIT) can also be employed to control the vector population. Several agriculturally important insect pests are sterilized using ionizing radiation from radioactive isotopes such as ${ }^{60} \mathrm{Co}$. However, these vectors are poor in health and are less effective in competing with wild type males. Therefore, the intended purpose of population control is not achieved. This technique is mainly used to control Anopheles sp. but it could also be employed for the control of Aedes sp. if basic information about their mating ecology is determined (Benelli, 2016). The strategy of using sterile males to induce sterility in wild fertile females can be used to reduce the insect population over a period of time. Using a suppression subtractive hybridization technique, 37 genes have been identified that are predominantly expressed in the testes of Ae. aegypti. A subset of 10 genes was chosen for RNAi-mediated knockdown to induce male sterility. It was observed that $9 / 10$ knockdowns introduced male sterility in more than $50 \%$ of males, with reduced fecundity in the remaining insects (Whyard et al., 2015; Singh et al., 2016). In Ae. aegypti females, physiological and behavioral changes occur after mating. A subset of genes is activated to induce blood feeding and ovigenesis. Therefore, mating directly influences the vectoral capacity of Ae. aegypti by directing it to blood feeding and oviposition. Information regarding the post-mating changes in gene expression profile may be useful in developing strategies against the insect (Alfonso-Parra et al., 2016). Sterlization through $\gamma$-irradiation requires radio-isotopes and therefore poses health risk while handling it. Male sterilization through RNAi is though seemingly a promising strategy, major setback of this approach is the financial constraints faced during the largescale application of this technique. Moreover, validation of the methodology adopted in the field is of utmost importance (Alphey et al., 2010; Weaver et al., 2016).

A pictorial representation of salient prevention and control measures of mosquito vector transmitting ZIKV is depicted in Figure 2.

\section{Transmission Blocking Vaccines (TBVs)}

Mosquitoes are developing resistance against the chemical insecticides that are commonly being used for their population control (Benelli, 2015). Hence, alternative strategies need to be 
designed and adopted for their efficient control. One of such recent approaches is the use of vaccines that can block the transmission of infectious agents from the vector (mosquito) to the host. These vaccines are termed as transmission blocking vaccines (TBVs) or "altruistic vaccines" (Londono-Renteria et al., 2016). The person who receives the vaccine may or may not be protected from the infectious agents but their neighbors will be protected; since the mosquitoes which bite the vaccinated person picks up the antibodies and thus the sites specific for infectious agent binding in the mosquitoes will be blocked by these antibodies (Londono-Renteria et al., 2016). Though, it seems weird that neighbors are only protected when the vaccine is administered to another person but due to the theory of herd immunity even the vaccinated person will also get protection in the long run (Dinglasan and Jacobs-Lorena, 2008). Although, this approach seems fascinating but it need assessment for its safety to the human health viz. autoimmune disorders (Kaslow, 1997). One important consideration to be take care is the maintenance of antibody titre in the vaccinated person as the antigen is not of human origin but is intended for mosquitoes (Coutinho-Abreu and Ramalho-Ortigao, 2010; Neelakanta and Sultana, 2015). To tackle this problem, suitable adjuvants can be employed such as IMX313 (a chicken complement C4b-binding protein oligomerization domain), exoprotein from Pseudomonas aeruginosa $\mathrm{A}$ and the outer membrane protein complex of Neisseria meningitides serogroup B (Qian et al., 2007; Li et al., 2016).

Presently, TBVs are under study for West Nile Virus and Dengue Virus, where these are designed to target the mosquito proteins that are essential for infection setup. Several targets have been identified for the development of TBVs against West Nile Virus like Ae. aegypti C-type lectin (mosGCTL-1) and similarly for Dengue Virus like mosGCTL-3, CRVP-379, CPB-1 (Isoe et al., 2009; Cheng et al., 2010; Colpitts et al., 2011; Bhatt et al., 2013; Liu et al., 2014; Tham et al., 2014). In silico analysis of three proteins, namely aegyptin, D7 and Sialokinin of Ae. Aegypti, was studied to identify B- and Tcell epitopes among these salivary proteins. These proteins are essential for the viral transmission between vector and host. Two B-cell epitopes LAALHVTAAPLWDAKDPEQF and TSEYPDRQNQIEE LNKLCKN were identified for D7 long form and D7 short form, respectively. Similarly, two T-cell epitopes MTSKNELDV and YILCKASAF for D7 long form and D7 short form, respectively, were identified (Sankar et al., 2017). These candidates can be further exploited for developing the TBVs that can prevent virus transmission to host. Eventhough, this technology is in its infancy, TBVs seems to be a promising avenue to prevent dreadful diseases that are transmitted through arthropods. Hence, such targets have to be timely identified for ZIKV so that TBVs can be developed for prevention of ZIKV transmission among the human population. Ultimately this approach will be especially beneficial for developing countries where the health care system is challenged economically (Londono-Renteria et al., 2016). The possible mechanism of TBVs has been picturized in Figure 1.

Different strategies to prevent and control mosquitoes are summarized in Table $\mathbf{1 .}$

\section{Prevention and Control Strategies for Human ZIKV Infection}

Apart from controlling the vector population that is involved in the transmission of ZIKV, it is also essential to adopt preventive measures at the individual level by the use of vaccines or employing strategies interfering the non-vectoral transmission of ZIKV. Nonetheless, as of now there is no commercial ZIKV vaccine in the market, but owing to the rapid pace of research in vaccine development, time is not far away for the availability of an effective ZIKV vaccine.

\section{Vaccines against ZIKV Infection}

The major strategy that can be employed for the effective control of ZIKV infection is the use of vaccine, which is yet in its primitive stage but is gaining high interest among researchers worldwide. Several vaccine platforms are currently under way for the development of an effective vaccine to prevent ZIKV infection (Asif et al., 2017; Barzon and Palù, 2017; Fernandez and Diamond, 2017; Munjal et al., 2017a). Due to the alarming nature of ZIKV and its potential threat to human population, within nearly 2 year of announcing ZIKV as an emergency by WHO, more than 40 vaccine candidates have been reported to be under preclinical study, 7 are in phase I trial and one is in its phase $2 \mathrm{~b}$ trial. Of note, the hemagglutinin subunit 1 (HA1/ H1) protein of influenza virus pdmH1N1 and the $\mathrm{E}$ protein of ZIKV shares similarity in frequency component (0.295) and thus the neutralization of ZIKV can happen by the antibodies generated against the pdmH1N1 H1 protein, ultimately affecting the cellular entry of ZIKV. Thus, proposal had been put forward to employ influenza vaccine (seasonal) consisting of the component of pdmH1N1 in order to prevent the spread of ZIKV (Veljkovic and Paessler, 2016; Zhao et al., 2016). The recent advancements in designing and developing vaccines against ZIKV are presented in the following section.

\section{Inactivated vaccines}

Inactivated vaccines are prepared through the killing of the pathogenic organism and immunizing host along with an adjuvant. Inactivated vaccines can be given to even immune compromised individuals; however, these require repeated immunizations to achieve the protective antibody titers. Inactivated vaccines are available for several flaviviruses such as Yellow Fever virus, West Nile fever virus, Japanese encephalitis virus, and others. An India based vaccine manufacturer, Bharat Biotechnologies, Hyderabad, India has initiated the efforts to develop inactivated ZIKV vaccine in early 2013 before the ZIKV disease emerged to Brazil as an epidemic and it is currently in its phase I clinical trial (Sumathy et al., 2017). There was protection of monkeys against Asian ZIKV strain which had prior exposure to African lineage prototype MR766 ZIKV strain. This observation explored the possibility of development of the vaccines that can protect against all lineages of ZIKV (Dowd et al., 2016a; Dyer, 2016). This African lineage prototype MR766 is in the pipeline for development of an inactivated ZIKV vaccine. Another formalin-inactivated vaccine named ZIKV purified inactivated virus (ZPIV), developed by Walter Reed Army Institute, United States of America (USA), displaying 


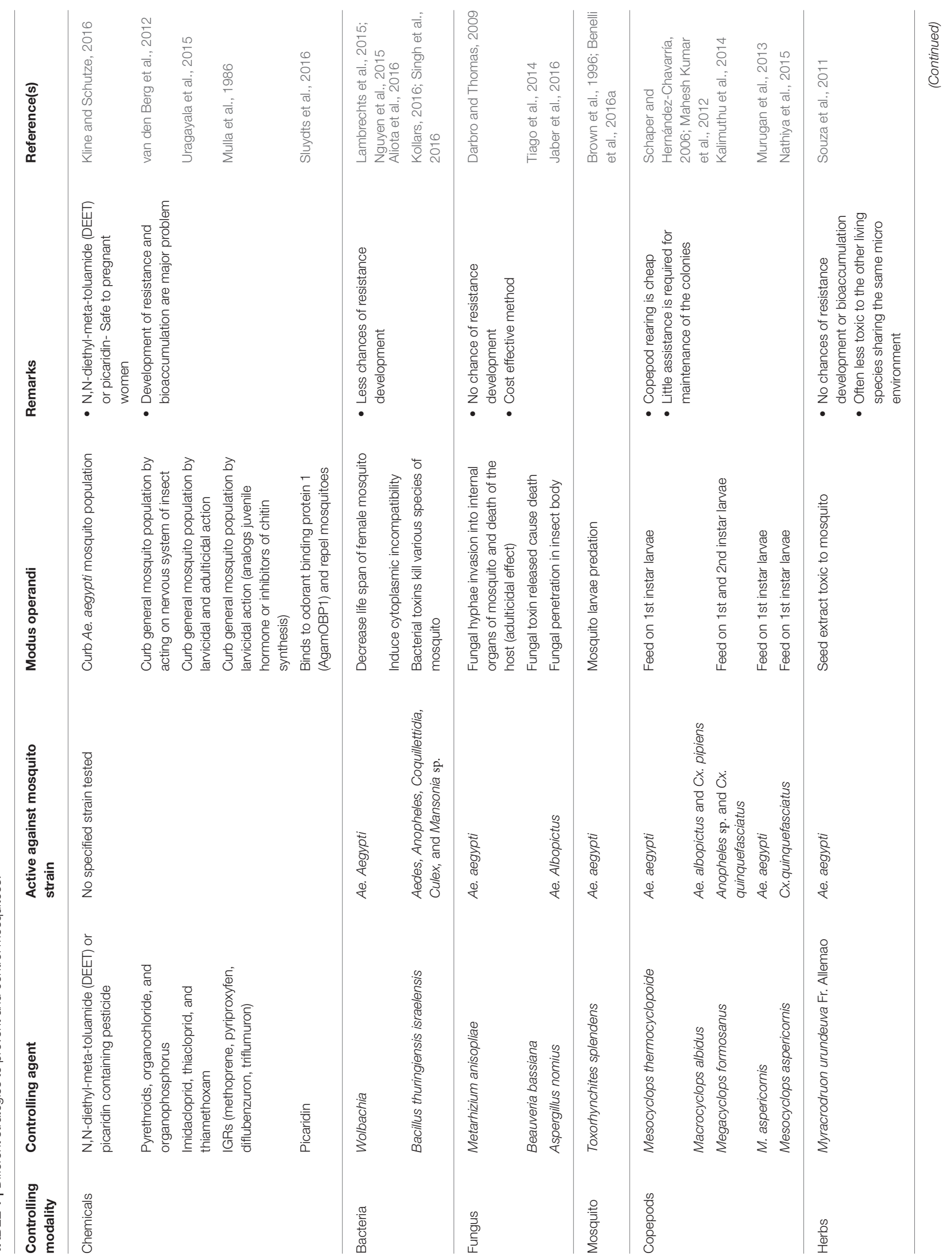




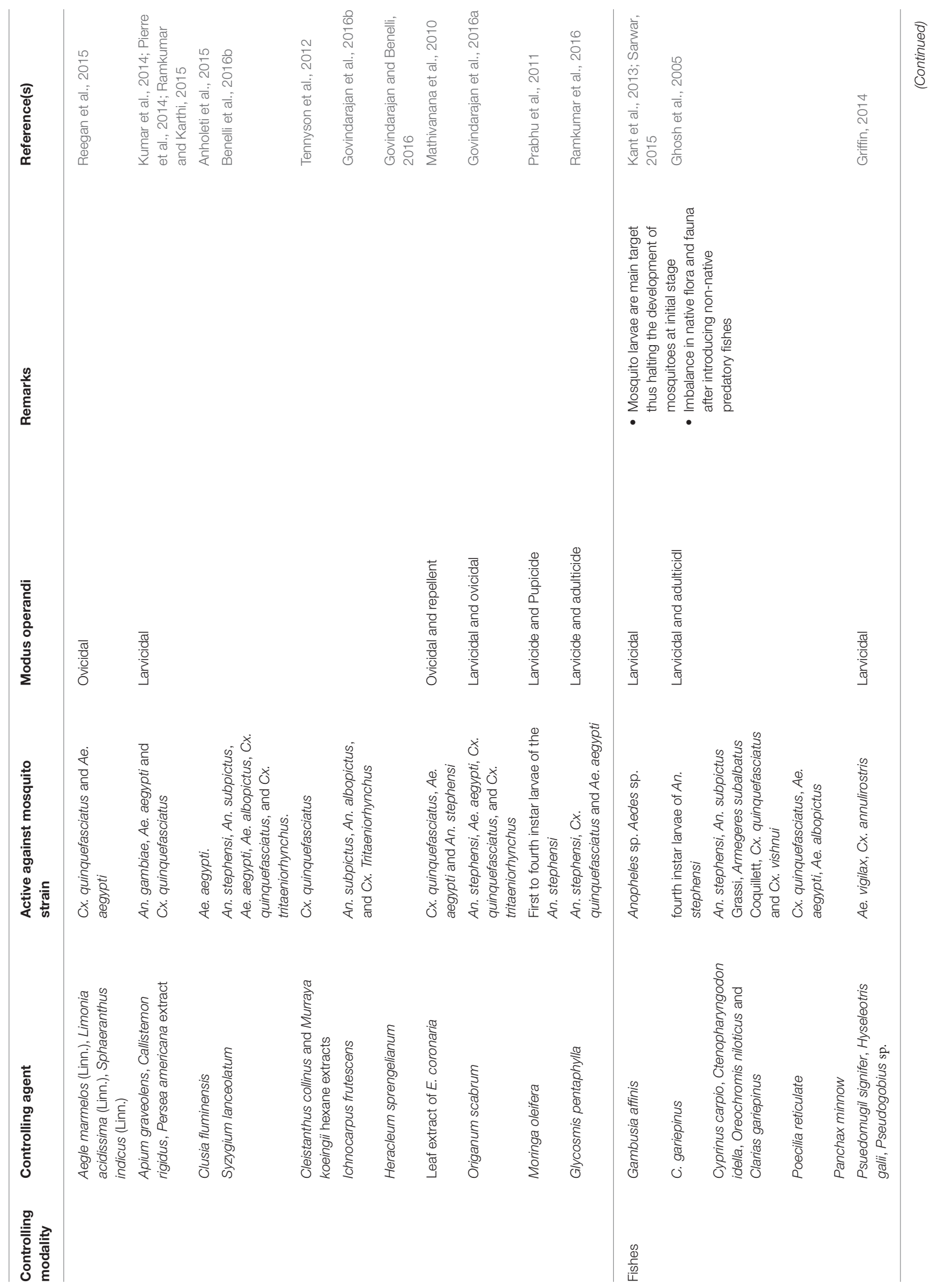


Singh et al.

Zika Virus: Prevention and Control Strategies
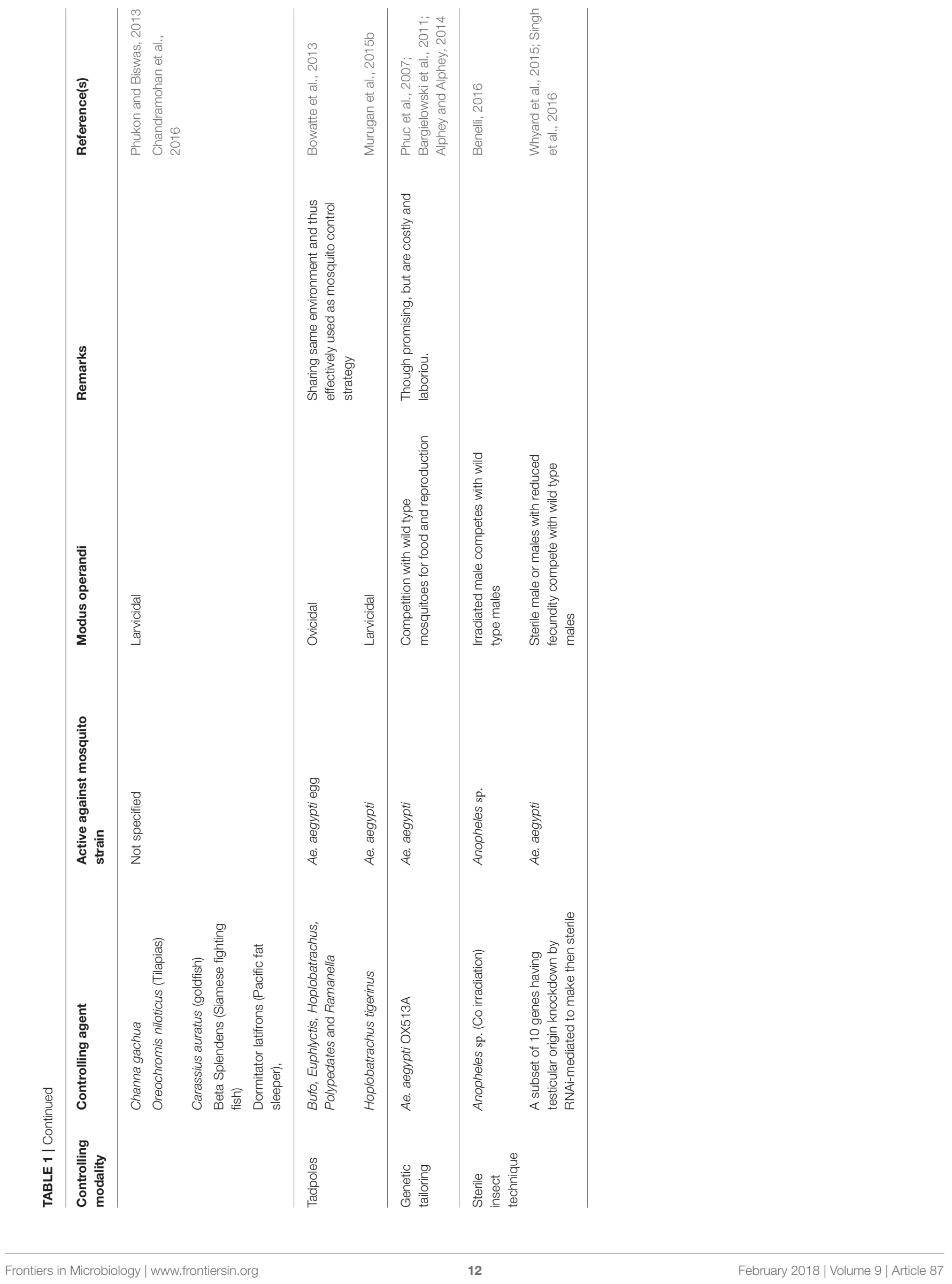
better protective efficacy in monkeys and mice, is also in phase I clinical trial (Larocca et al., 2016). An experimental study of this vaccine with AG 129 mice showed that there was complete protection against challenge with both homotypic and also heterotypic ZIKV strains. Phase I clinical studies conducted on 67 participants employing ZPIV revealed seroconversion after administration of 2 doses of the vaccine and there was minimal side effect (Modjarrad et al., 2017). Further studies are warranted for employing the new generation vaccine adjuvants and also to improve the immunogenicity before the inactivated ZIKV vaccine can hit the commercial market.

\section{Live attenuated ZIKV vaccine}

Live attenuated vaccines are made by weakening the natural virus or bacteria using heat, chemical or genetic manipulation. Such vaccines modulate both the arms of the immune system, humoral and cell mediated, and even with fewer doses sufficient level of protection is obtained. A Cambodian ZIKV strain candidate (FSS13025) with deletion of 10 nucleotides in the $3^{\prime}$ untranslated region was developed to create a live attenuated ZIKV vaccine. A study in A129 mice (type I interferondeficient mice) showed that the developed vaccine candidate was completely attenuated, elicited immunity and rendered protection against ZIKV challenge (Shan et al., 2017a). Another study with the live attenuated ZIKV vaccine trial in the pregnant mice indicated that there was minimal level of ZIKV RNA in placenta, maternal and fetal tissues on 6 and 13 days of embryonic life after vaccination. Similarly, vaccination of male mice also protected testicular damage and oligospermia due to ZIKV (Shan et al., 2017b). Recently, a patent (WO2017156511A1) has been granted for the development of live attenuated ZIKV vaccine (Whitehead et al., 2017). Codagenix, New York, USA, reported the development of ZIKV vaccine (CDX-ZKV) employing codon deoptimization technology. A chimeric ZIKV vaccine employing pre-membrane (prM) and Envelope (E) genes of ZIKV in a backbone of attenuated DENV2 is under construction to fight against ZIKV infection (Morabito and Graham, 2017).

\section{DNA based vaccines}

Nucleic acid vaccine designing is the promising platform that is in limelight during the recent years for the progressive development of an effective ZIKV vaccine. DNA vaccines coding prM-E protein genes of ZIKV have been developed and are in clinical trial. Inovio Pharmaceuticals, Pennsylvania, USA, has developed a DNA vaccine, GLS-5700, which is the first ZIKV vaccine to enter the clinical trial. Vaccine Research Center (VRC), National Institute of Allergy and Infectious Diseases, National Institutes of Health, USA has also developed two ZIKV DNA vaccines, namely VRC5288 (ZIKV and Japanese Encephalitis chimeric vaccine) and VRC5283 (ZIKV prM-E vaccine), which are in phase I clinical studies (Morabito and Graham, 2017). Phase I study conducted with 80 participants for VRC5288 and 45 participants for VRC5283 revealed that these vaccines are safe with minimal side effects. The participants (14 nos.) who received split dose vaccine of VRC5283 had 100\% antibody response and based on such encouraging results VRC5283 was suggested for next level clinical trial (Gaudinski et al., 2017). As per the recent report, VRC5283 has now entered phase IIb clinical trial. Both these DNA vaccines provided better immunity and controlled viremia in 17 out of 18 rhesus monkeys when tested along with another vaccine candidate VRC8400 (Dowd et al., 2016b). Though, DNA vaccine strategy appears fascinating, few limitations are also associated with it such as the need for large quantity of DNA to immunize and further there may be a risk of its integration into the host genome.

\section{mRNA based vaccines}

The mRNA vaccine is another type of nucleic acid based vaccine which gets translated immediately after its entry into the cell, unlike DNA vaccine that needs entry to the nucleus for initial transcription followed by the translation. The mRNA vaccines have emerged as better alternative to the DNA vaccine, as these does not integrate with the host genome and thus offers higher safety in comparison to the DNA vaccine. Such a vaccine may be directly transfected to cytoplasm so can evade problems associated with the nuclear delivery. The mRNA based vaccines have several other advantages like easy delivery with liposomes, cationic polymers (Fotin-Mleczek et al., 2011), gene gun and electroporation ( $\mathrm{Cu}$ et al., 2013), and these binds to pattern recognition receptor and can act as self-adjuvant (Fotin-Mleczek et al., 2011). Nucleoside-modified mRNA encompassing ZIKV glycoprotein (preM-E) enveloped in lipid nanoparticles has been shown to induce strong humoral response and initiate T-cell immunity in mice and macaques with a single immunization using $30 \mu \mathrm{g}$ of ZIKV prM-E mRNA-LNP construct (Richner et al., 2017). The use of nanoparticles here ensured the intracellular delivery of mRNA, a critical requirement for a potential vaccine candidate. The mRNA based self-replicating technology also may be developed, but its limitation that vaccine itself may produce innate immune response and toxicity must be addressed before use. A single epitope IGVSNRDFV from the ZIKV E protein has been recently identified, which is conserved across all the ZIKV clades and to which strong CD8+ T-cell response was found to be induced in immunized C57BL/6 mice (Chahal et al., 2017). This approach provides an excellent mechanism to develop a vaccine without requiring a recombinant glycoprotein or reference virus stock and may also have the potential to be generated readily at the time of outbreaks in emergency situations. More recently, a longlasting immunity has been reported to be provided in nonhuman primates by employing mRNA-LNP (lipid nanoparticleencapsulated nucleoside modified mRNA) thereby appearing to be a putative candidate vaccine in the coming years (Pardi et al., 2017; Richner et al., 2017).

\section{Vectored vaccine}

Vectored vaccine is another approach for the development of ZIKV vaccines. Recently, measles vector based ZIKV vaccine has been developed by Themis Biosciences expressing the ZIKV prM-E proteins. Under experimental condition, a single dose of this vectored vaccine protected monkey from two different strains of ZIKV and the vaccine is presently in its preclinical studies. Due to the alarming concern about the antibodydependent enhancement (ADE) of Dengue/ZIKV as a result of 
the use of ZIKV envelope immunogens as vaccine candidates, there is a search for an alternative vaccine strategy. Thus, viral vectored vaccine expressing ZIKV NS1 can be a promising alternative to prevent the ADE (Brault et al., 2017). Modified vaccinia Ankara vectored ZIKV expressing NS1 and Vesicular Stomatitis Virus vectored ZIKV expressing prM-E have been developed by Geovax and Harvard, respectively. An effective long-term durable protection provided by such vaccine is essential in order to fight against ZIKV infection. As, most of the challenge studies were carried out following ZIKV vaccines during the peak immune status; hence, a clear picture regarding the durability of the vaccines is not known. Immunization of rhesus monkeys with an adeno vectored ZIKV vaccine followed by dual immunization with purified inactivated ZIKV vaccine provided protective immune response even at 1 year of vaccination (Abbink et al., 2017). Thus, this approach can provide immunity against ZIKV atleast for 1 year, which can be further studied to know the exact protection period. An adenovirus serotype 5-vectored vaccine- Ad5.ZIKV-Efl (virus vectored) has also been recently developed that is under clinical consideration (Kennedy, 2016; Kim et al., 2016). Other approaches like subunit vaccine are also being evaluated for the development of ZIKV vaccine by different firms like PaxVax, VBI Vaccines, and NewLink Genetics (Morabito and Graham, 2017).

\section{Cytotoxic T lymphocyte vaccine}

Cytotoxic $\mathrm{T}$ lymphocyte (CTL) response constitutes an imperative arm of the host defense system to render protection against any of the infectious pathogens. CD4+ T-cell epitopebased DNA vaccine has been found highly immunogenic and to elicit the significant protective response. Human Leukocyte Antigen-antigen D Related (HLA-DR) is a major histocompatibility class II (MHC II) cell surface receptor, which along with 9-amino acid long stretch of peptide/epitope forms a ligand for T-cell receptor (TCR). Such peptide sequences may be predicted using the different algorithms like TEPITOPE and ProPred. By this approach "promiscuous" CD4+ T-cell epitopes from the conserved $\mathrm{E}$ and $\mathrm{M}$ proteins of ZIKV can be predicted which are able to bind with multiple HLA-DR molecules, and hence could pave way for developing a CTL based vaccine against this virus (Cunha-Neto et al., 2017).

\section{Lysosome-associated membrane protein vaccine}

Carboxyl terminal domain of the protein associated with the lysosome-associated membrane protein (LAMP) is used to direct the antigen to the MHC II vesicular compartment of the antigen-presenting cells. LAMP1 and LAMP2 are the most abundant lysosomal proteins. These are essential for maintaining membrane integrity of the lysosome and release of hydrolytic enzymes (Jiang et al., 2015). The cytoplasmic tail of LAMP1 is comprised of 11 amino acids (RKRSHAGYQTI), and in particular the last 4 amino acid residues (YQTI), are determinant for the proteins' lysosomal targeting (Lu, 2003). A DNA chimera constructs having West Nile virus preM-E and LAMP when used to immunize mice, it elicited significant antibody and longterm neutralization titers in comparison to those mice that were immunized with the construct expressing the untargeted antigen
(Anwar et al., 2005). Immunization with a DNA construct having Yellow fever virus (YFV) matrix and envelop protein fused with LAMP sequence showed higher neutralization titers, that protected mice from intracerebral challenge with the YFV virus (Dhalia et al., 2009). Although, no attempt has been made to develop such LAMP based vaccine for ZIKV, in near future such vaccine may be developed with proper efficacy verification of the vaccine.

\section{Computer-aided vaccine designing}

It is another platform that led to the identification of various ZIKV candidate targets like E, NS3 and NS5 proteins which can be employed for development of peptide vaccines (Usman Mirza et al., 2016). An in silico analysis carried out on the ZIKV NS1 gene revealed that it is conserved and distributed among all different isolates of ZIKV. Of note, this study resulted in the identification of NS1 of ZIKV that has the potential to elicit the immune response thereby preventing ZIKV infection (Dos Santos Franco et al., 2017). Thus, it makes a hope for commercially viable effective Zika vaccine in the near future to prevent ZIKV infection among the human population. Nevertheless, molecular dynamic studies are needed to analyse the immunogenic CTL epitopes for the presentation of MHC-antigen as well as to evaluate its stability. Docking of approximately 15 CTL epitopes (conformational) with multiple MHCI proteins has been done recently. Side-byside simulation of the conditions was also performed for the purpose of their interaction (Usman Mirza et al., 2016). The results would be enormously helpful for designing the peptide based vaccines as the data may provide with the preliminary bunch of peptides. Among the ZIKV T-cell epitopes certain peptides viz., QTLTPVGRL and IRCIGVSNRDFV are found highly antigenic in nature (Ashfaq and Ahmed, 2016).

Figure 3 summarizes the different vaccine platforms available for ZIKV prevention and control.

\section{Other Prevention and Control Strategies}

Transmission through the vectors is not the sole way of the ZIKV spread. There are several other routes (non-vector borne) which must be taken into consideration in order to design the control strategies against the spread of this virus. As far as the issues related to complications of health is concerned there must be general awareness among the public so that basic cleanliness measures can be adapted to confirm elimination of breeding space for vector larvae (Grischott et al., 2016). ZIKV is reported to transmit sexually, hence safe sexual contact is a pre-requisite for prevention of viral infection and also sexual intercourse is not advised for 6 months from the time of onset of signs in male partners or from the time of diagnosis (Musso et al., 2015; Mead et al., 2017). Practice of safe sex in high risk areas should be considered as an important precautionary measure. It is advisable to avoid sexual intercourse if traveling in such an area or if one partner is infected with ZIKV (Rather et al., 2017). Those planning to conceive after their visit to endemic areas must wait at least 28 days to allow a 2 week incubation period and another 2 weeks for the period of viremia to end. Visitors from such areas must be kept under surveillance for symptoms 


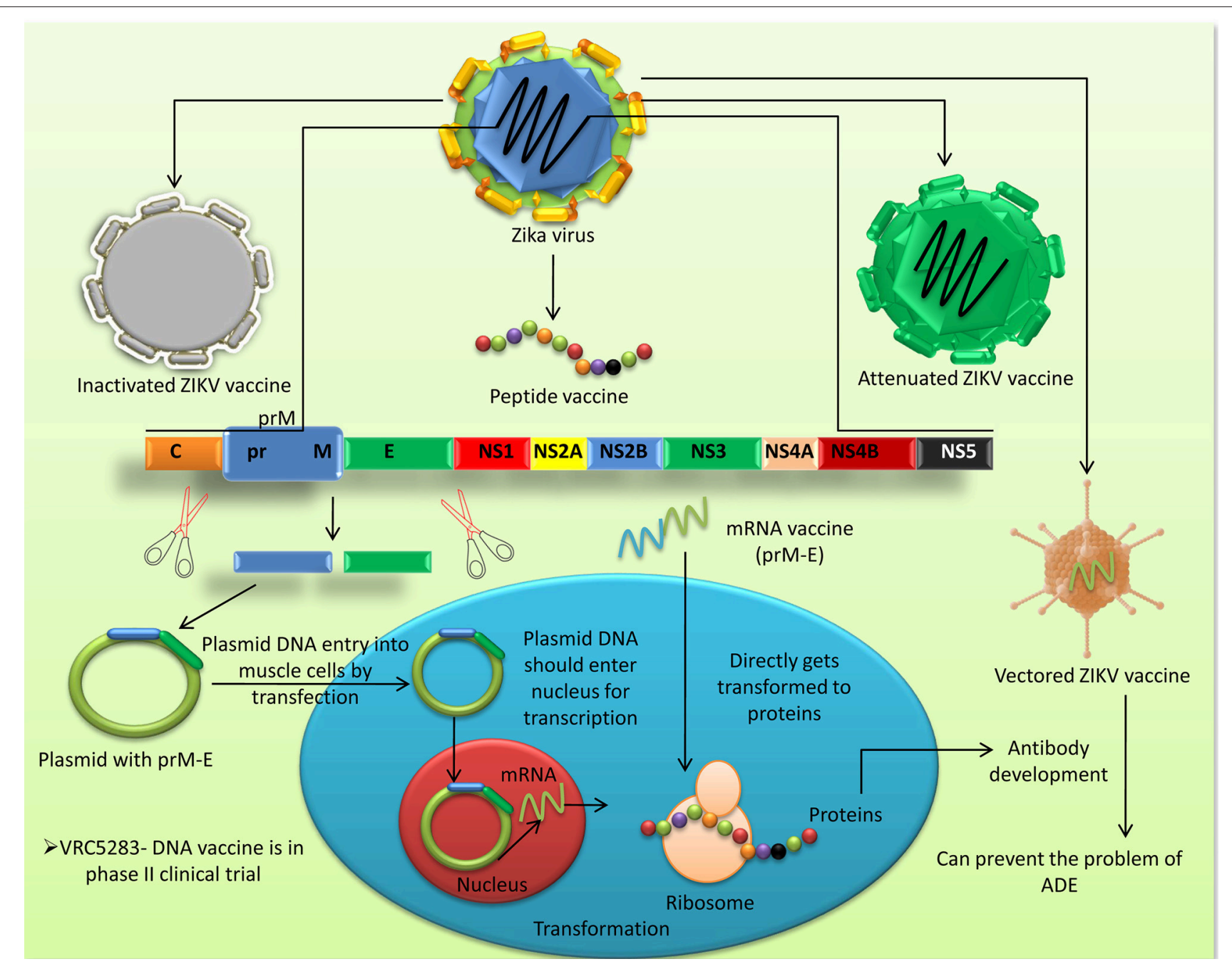

FIGURE 3 | Different vaccine platforms available for prevention and control of ZIKV infection in humans.

for at least 1 month (Maharajan et al., 2016; Singh et al., 2016; Krow-Lucal et al., 2017). Parental care and use of contraceptives should be provided in ZIKV-endemic countries to minimize the incidence of ZIKV-associated microcephaly (Sharma and Lal, 2017). As ZIKV is known to be present in semen (Mansuy et al., 2016) and saliva (D'Ortenzio et al., 2016), therefore, the use of contraceptives is emphasized (Atkinson et al., 2016; D'Ortenzio et al., 2016; Mansuy et al., 2016). Tests conducted for the persistence of ZIKV in biological fluids revealed that only semen remains positive for ZIKV-RNA after 27 and 62 days (Atkinson et al., 2016). However, a subsequent study showed the prolonged presence of ZIKV in semen as long as 144 days after the onset of clinical symptoms (Huits et al., 2017). Similarly, another study showed the persistence of ZIKV in semen even on 188 days after the onset of symptoms in an Italian traveler returning from Haitii (Nicastri et al., 2016).

Although, the presence of infective ZIKV particles has been reported in breast milk (Dupont-Rouzeyrole et al., 2016), there is no report of its transmission to neonates. As it is presumed that the advantages of breast feeding are greater than the possible risk of ZIKV transmission and therefore, the CDC has recommended that infected mothers and mothers living in endemic areas continue to breast feed their neonates. Blood transfusion can also disseminate ZIKV if preventive measures have not been taken timely (Vasquez et al., 2016). Thus, inactivation of the virus by the way of pasteurization and solvent/detergent treatment along with virus removal using filters with a $40 \mathrm{~nm}$ pore size, can effectively reduce viral load in the plasma-derived medicinal products (Blümel et al., 2016; Farcet and Kreil, 2017; Kühnel et al., 2017). Amotosalen combined with UV light has also shown to inactivate ZIKV in fresh or frozen plasma (Aubry et al., 2016; Santa Maria et al., 2017). ZIKV has been reported to be inactivated for infectious particles by $6.57 \log _{10} \mathrm{TICD}_{50} / \mathrm{mL}$ and for viral RNA by $10.25 \log _{10}$ copies/mL in frozen plasma by using the combination of amotosalen and UV light (Aubry et al., 2016; Musso et al., 2017). Recently, amustaline (S-303) and glutathione 
(GSH) have been identified to inactivate ZIKV in red blood cells (Laughhunn et al., 2017). The high risk group of ZIKV includes health workers, hence hygienic practices should be employed to minimize the risk of spread of ZIKV within the inmates of the hospital (Rather et al., 2017).

In the initial week following ZIKV infection, bites of Aedes mosquitoes should be avoided. At the same time, it is advisable for the patients to remain under bed-nets. The health workers must take precautionary measures to avoid infection of hospitalized patients from such health workers. Use of insect repellant like $\mathrm{N}, \mathrm{N}$-diethyl-3-methylbenzamide, 3-(N-butyl- $\mathrm{N}$ acetyl) amino propionic acid ethyl-ester (icaridin) should be encouraged (Sikka et al., 2016; Rather et al., 2017). People traveling to endemic areas must be properly educated about the use of mosquito repellents and mosquito nets during their travel. Pregnant women must avoid visiting such areas due to the risk of brain malformation of the fetus. If they have already traveled to an endemic region, they must be kept under proper medical supervision. Surveillance and monitoring should be at its highest level at airports, harbors, and other ports of entry to prevent entry of ZIKV from endemic countries (Marano et al., 2016). Mosquitoes control programs combined with surveillance study within 200 meters of ZIKV infected persons at South Korea revealed that there were no cases of ZIKV after vector control measures. Hence, monitoring and surveillance is of utmost importance for the prevention and control of Zika disease (Chang et al., 2017).

Last but not the least, especially the societies which are vulnerable to the emerging threats of ZIKV infection should be addressed appropriately by the policy makers at the government level. The current global trend of climate changes that influences the vector density cannot be ignored at this time. In developing countries, certain crucial measures viz., advance planning and development of infrastructure prior to the disease outbreaks are often neglected that make the situation grave. So, such priorities should be set timely in this regard for efficient prevention and control ZIKV infection and limiting its massive spread. Nevertheless, a sense of responsibility and collective efforts at the level of both government as well as the public are the need of hour (Dasti, 2016; Mourya et al., 2016).

The possible ways of ZIKV transmission, its prevention and control measures in humans are indicated in Figure 4.

\section{CONCLUSIONS AND FUTURE PERSPECTIVES}

The involvement of the Aedes mosquito in the transmission of ZIKV has gained global attention. High density human population, lack of immunity and mutations in the virus helps in the propagation of the virus. Additionally, global warming has acted as a catalyst. Eventhough, there are many modes of ZIKV transmission, priority must be given to the control of mosquitoes. Hence, more focus is needed to adopt appropriate mechanical, biological and chemical measures to prevent or inhibit their breeding and thus, control the mosquito population. Use of chemicals has the disadvantages of development of resistance and bioaccumulation; hence in the recent time, a shift has been seen toward biopesticides. Several plant extracts and essential oils are found effective against mosquito control. The spread of viruses by mosquitoes can be checked using bacteria such as Wolbachia pipientis and alpha-proteobacterium, which may transfer both horizontally and vertically. Genetic engineering techniques using siRNA to knock down testes-specific genes, resulting in male mosquito sterility, may also be employed. The use of fungi to control the Ae. aegypti mosquito seems to be promising, but further research is needed to determine the viability, infectivity, and spore persistence in the field. The use of fish seems to be a good option but due care should be taken in selecting the kind of fish for predation, as non-native species can cause problem of invasive behavior, and spoiling aquatic microenvironment.

Though, currently there is no commercial vaccine available in the market against ZIKV, however presently much advancement in this direction have been initiated with promising outcomes by several group of researchers worldwide for the development of an effective vaccine. Several vaccine candidates are now in preclinical and clinical phase studies and expected to reach the market soon with possibilities to prevent ZIKV infection in humans. Recently, the use of transmission blocking vaccines (TBV) preventing the spread of disease from infected and vaccinated person to naïve person have shown great promise. If employed successfully then the whole community can be benefited as the non-vaccinated person also gets protection. Exploiting the fields of immune profiling, bioinformatics, cloud computing, vaccinomics, reverse immunology and other advances to their full potential applications would ultimately make possible the designing and developing of efficient, more convenient and cost effective ZIKV vaccines in the near future.

The use of genetically modified vectors has many benefits, but it will be important to educate government authorities, public health officials, and scientists regarding the effectiveness of this strategy. Further research is required to analyze the cases of ZIKV infection to determine the relationship between the virus and genetic mutations of the Aedes mosquito. This will increase our understanding of the mechanisms of the transmission cycle of the virus and the reasons for favoring this specific mosquito. Genetically modified mosquitoes, which are not potent to reproduce and can compete with wild type mosquitoes are needed. However, the location must be taken into consideration before conducting such small-scale experiments in the field. The use of mosquito-repelling herbal products should also be encouraged, since these are safe for any age and sex and could be used by pregnant women without fear of adverse effects. Health workers must be protected to avoid the spread of infection to hospitalized patients and utmost care must be taken while donating blood or organs.

It must be noted that globalization has facilitated the rapid spread of ZIKV infection in large scale and to widespread territories worldwide. The infectious agent is allowed to thrive well due to change in climate globally along with overcrowding in the urban areas. So, it is high time to re-think about these issues and rebuild our infrastructure as far as the public health is concerned and to develop effective strategies to control the disease. Apart from the well-established mosquito-borne mode 


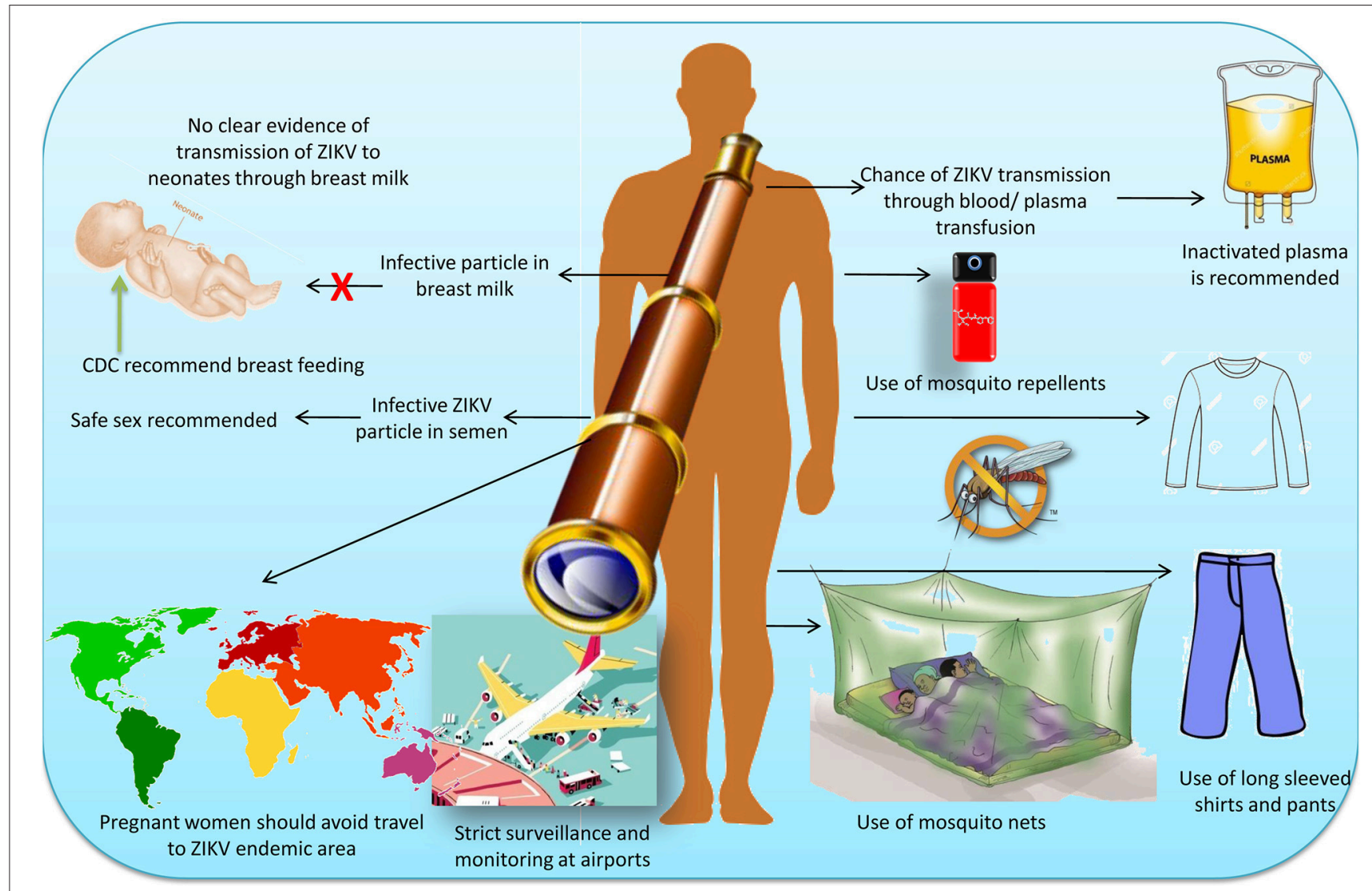

FIGURE 4 | Possible ways of Zika virus transmission, its prevention and control measures in humans.

of ZIKV transmission, there is need to converge our focus on the other modes of transmission of ZIKV, as yet our knowledge regarding the other possible modes is hazy. This would help to carve out better prevention and control strategies against ZIKV. There is need to advise pregnant mothers to avoid traveling to ZIKV infection endemic areas, educate the public regarding the disease outcome and progress so far, and to add to the current epidemiological data. Lastly, but importantly, researchers and scientists must share data on the status of mosquito population control between countries. The ZIKV cases should be studied in detail in order to check the correlation between the infectious agents and mutation in the Aedes mosquito population. This, in turn, will help to understand the reasons for this particular type of mosquitoes being the carrier of ZIKV infection. Side by side the development of the vaccine should be carried out at a rapid pace so as to reach the commercial market soon.

\section{REFERENCES}

Abbink, P., Larocca, R. A., Visitsunthorn, K., Boyd, M., De La Barrera, R. A., Gromowski, G. D., et al. (2017). Durability and correlates of vaccine protection against Zika virus in rhesus monkeys. Sci. Transl. Med. 9:eaao4163. doi: 10.1126/scitranslmed. aao4163

\section{AUTHOR CONTRIBUTIONS}

All the authors substantially contributed to the conception, design, analysis and interpretation of data, checking and approving final version of manuscript, and agree to be accountable for its contents. RS, KD, RK, and AM initiated this review compilation; RK designed tables and KK designed the figures; SC, AM, KK, and RT updated different intervention strategies; YM and RS reviewed virological aspects and analyzed data; $\mathrm{KD}$ and $\mathrm{RB}-\mathrm{M}$ reviewed, analyzed, and edited.

\section{ACKNOWLEDGMENTS}

All the authors acknowledge and thank their respective Institutes and Universities.

Achee, N. L., Gould, F., Perkins, T. A., Reiner, R. C. Jr., Morrison, A. C., Ritchie, S. A., et al. (2015). A critical assessment of vector control for dengue prevention. PLoS Negl. Trop. Dis. 9:e0003655. doi: 10.1371/journal.pntd.0003655

Adalja, A., Sell, T. K., McGinty, M., and Boddie, C. (2016). Genetically modified (GM) mosquito use to reduce mosquito-transmitted disease in the US: a community opinion survey. PLoS Curr. 25:8. doi: 10.1371/currents.outbreaks.1c39ec05a743d41ee39391ed0f2ed8d3 
Adeosun, C., Bamidele, I., salau, B., and Ayorinde, A. (2016). Essential oil from the stem bark of Casuarina equisetifolia exhibits mosquitocidal potential. J. Pathol. Pest Manag. 3, 53-62.

AhbiRami, R., Zuharah, W. F., Thiagaletchumi, M., Subramaniam, S., and Sundarasekar, J. (2014). Larvicidal efficacy of different plant parts of railway creeper, Ipomoea cairica extract against dengue vector mosquitoes, Aedes albopictus (Diptera: Culicidae) and Aedes aegypti (Diptera: Culicidae). J. Insect Sci. 14:180. doi: 10.1093/jisesa/ieu042

Alfonso-Parra, C., Ahmed-Braimah, Y. H., Degner, E. C., Avila, F. W., Villarreal, S. M., Pleiss, J. A., et al. (2016). Mating-induced transcriptome changes in the reproductive tract of female Aedes aegypti. PLoS Negl. Trop. Dis. 10:e0004451. doi: 10.1371/journal.pntd.0004451

Aliota, M. T., Peinado, S. A., Velez, I. D., and Osorio, J. E. (2016). The wMel strain of Wolbachia reduces transmission of Zika virus by Aedes aegypti. Sci. Rep. 6:28792. doi: 10.1038/srep28792

Alphey, L., and Alphey, N. (2014). Five things to know about genetically modified (GM) insects for vector control. PLoS Pathog. 10:e1003909. doi: 10.1371/journal.ppat.1003909

Alphey, L., Benedict, M., Bellini, R., Clark, G. G., Dame, D. A., Service, M. W., et al. (2010). Sterile-insect methods for control of mosquito-borne diseases: an analysis. Vector Borne Zoonotic Dis. 10, 295-311. doi: 10.1089/vbz.2009.0014

Al-Qahtani, A. A., Nazir, N., Al-Anazi, M. R., Rubino, S., and Al-Ahdal, M. N. (2016). Zika virus: a new pandemic threat. J. Infect. Dev. Ctries. 10, 201-207. doi: $10.3855 /$ jidc. 8350

Anbu, P., Murugan, K., Madhiyazhagan, P., Dinesh, D., Subramaniam, J., Panneerselvam, C., et al. (2016). Green-synthesised nanoparticles from Melia azedarach seeds and the cyclopoid crustacean Cyclops vernalis: an eco-friendly route to control the malaria vector Anopheles stephensi? Nat. Prod. Res. 30, 2077-2084. doi: 10.1080/14786419.2015.1114935

Anholeti, M. C., Duprat, R. C., Figueiredo, M. R., Kaplan, M. A., Santos, M. G., Gonzalez, M. S., et al. (2015). Biocontrol evaluation of extracts and a major component, clusianone, from Clusia fluminensis Planch. \& Triana against Aedes aegypti. Mem. Inst. Oswaldo Cruz 110, 629-635. doi: $10.1590 / 0074-02760150103$

Anogwih, J. A., Makanjuola, W. A., and Chukwu, L. O. (2015). Potential for integrated control of Culex quinquefasciatus (Diptera: Culicidae) using larvicides and guppies. Biol. Control 81, 31-36. doi: 10.1016/j.biocontrol.2014.11.001

Anwar, A., Chandrasekaran, A., Ng, M. L., Marques, E., and August, J. T. (2005). West Nile premembrane-envelope genetic vaccine encoded as a chimera containing the transmembrane and cytoplasmic domains of a lysosomeassociated membrane protein: increased cellular concentration of the transgene product, targeting to the MHC II compartment, and enhanced neutralizing antibody response. Virology 332, 66-77. doi: 10.1016/j.virol.2004.11.022

Araújo, H. R., Carvalho, D. O., Ioshino, R. S., Costa-da-Silva, A. L., and Capurro, M. L. (2015). Aedes aegypti control strategies in Brazil: incorporation of new technologies to overcome the persistence of dengue epidemics. Insects 6, 576-594. doi: 10.3390/insects6020576

Armstrong, N., Hou, W., and Tang, Q. (2017). Biological and historical overview of Zika virus. World J. Virol. 6, 1-8. doi: 10.5501/wjv.v6.i1.1

Ashfaq, U. A., and Ahmed, B. (2016). De novo structural modeling and conserved epitopes prediction of Zika virus envelop protein for vaccine development. Viral Immunol. 29, 436-443. doi: 10.1089/vim.2016.0033.

Asif, A., Manzoor, S., Tuz-Zahra, F., Saalim, M., Ashraf, M., Ishtiyaq, J., et al. (2017). Zika virus: immune evasion mechanisms, currently available therapeutic regimens, and vaccines. Viral Immunol. 30, 1-9. doi: 10.1089/vim.2017.0046

Atkinson, B., Hearn, P., Afrough, B., Lumley, S., Carter, D., Aarons, E. J., et al. (2016). Detection of Zika virus in semen. Emerg. Infect. Dis. 22:940. doi: $10.3201 /$ eid2205.160107

Aubry, M., Finke, J., Teissier, A., Roche, C., Broult, J., Paulous, S., et al. (2015). Seroprevalence of arboviruses among blood donors in French Polynesia, 2011-2013. Int. J. Infect. Dis. 41, 11-12. doi: 10.1016/j.ijid.2015. 10.005

Aubry, M., Richard, V., Green, J., Broult, J., and Musso, D. (2016). Inactivation of $\mathrm{Zika}$ virus in plasma with amotosalen and ultraviolet A illumination. Transfusion 56, 33-40. doi: 10.1111/trf. 13271
Bargielowski, I., Nimmo, D., Alphey, L., and Koella, J. C. (2011). Comparison of life history characteristics of the genetically modified OX513A line and a wild type strain of Aedes aegypti. PLoS ONE 6:e20699. doi: 10.1371/journal.pone.0020699

Barrera, R., Amador, M., Acevedo, V., Caban, B., Felix, G., and Mackay, A. J. (2014). Use of the CDC autocidal gravid ovitrap to control and prevent outbreaks of Aedes aegypti (Diptera: Culicidae). J. Med. Entomol. 51, 145-154. doi: 10.1603/ME13096

Barzon, , L., and Palù, G. (2017). Current views on Zika virus vaccine development. Expert Opin. Biol. Ther. 17, 1185-1192. doi: 10.1080/14712598.2017.1346081

Benelli, G. (2015). Research in mosquito control: current challenges for a brighter future. Parasitol. Res. 114, 2801-2805. doi: 10.1007/s00436-015-4586-9

Benelli, G. (2016). Spread of Zika virus: the key role of mosquito vector control. Asian Pac. J. Trop Dis. 6, 468-471. doi: 10.1016/j.apjtb.2016.03.012

Benelli, G., Jeffries, C. L., and Walker, T. (2016a). Biological control of mosquito vectors: past, present, and future. Insects 7:52. doi: 10.3390/insects7040052

Benelli, G., Rajeswary, M., and Govindarajan, M. (2016b). Towards green oviposition deterrents? Effectiveness of Syzygium lanceolatum (Myrtaceae) essential oil against six mosquito vectors and impact on four aquatic biological control agents. Environ. Sci. Pollut Res. doi: 10.1007/s11356-016-8146-3

Berthet, N., Nakouné, E., Kamgang, B., Selekon, B., Descorps- Declère, S., Gessain, A., et al. (2014). Molecular characterization of three Zika flaviviruses obtained from sylvatic mosquitoes in the Central African Republic. Vector Borne Zoonotic Dis. 14, 862-865. doi: 10.1089/vbz.2014.1607

Bhatt, S., Gething, P. W., Brady, O. J., Messina, J. P., Farlow, A. W., Moyes, C. L., et al. (2013). The global distribution and burden of dengue. Nature 496 504-507. doi: 10.1038/nature12060

Blümel, J., Musso, D., Teitz, S., Miyabayashi, T., Boller, K., Schnierle, B. S., et al. (2016). Inactivation and removal of Zika virus during manufacture of plasma derived medicinal products. Transfusion 57, 790-796. doi: 10.1111/trf.13873

Bowatte, G., Perera, P., Senevirathne, G., Meegaskumbura, S., and Meegaskumbura, M. (2013). Tadpoles as dengue mosquito (Aedes aegypti) egg predators. Biol. Control 67, 469-474. doi: 10.1016/j.biocontrol.2013.10.005

Brault, A. C., Domi, A., McDonald, E. M., Talmi-Frank, D., McCurley, N., Basu, R., et al. (2017). A Zika vaccine targeting NS1 protein protects immunocompetent adult mice in a Lethal Challenge Model. Sci. Rep. 7:14769. doi: 10.1038/s41598-017-15039-8

Brown, M. D., Hendrikz, J. K., Greenwood, J. G., and Kay, B. H. (1996). Evaluation of Mesocyclops aspericornis (Cyclopoida: Cyclopidae) and Toxorhynchites speciosus as integrated predators of mosquitoes in tire habitats in Queensland. J. Am. Mosq. Control Assoc. 12, 414-420.

Callaway, E. (2016). Infected mosquitoes fight Zika. Nature 539, 17-18. doi: 10.1038/nature.2016.20878

Caragata, E. P., Dutra, H. L., and Moreira, L. A. (2016). Exploiting intimate relationships: controlling mosquito-transmitted disease with Wolbachia. Trends Parasitol. 32, 207-218. doi: 10.1016/j.pt.2015.10.011

Chahal, J. S., Fang, T., Woodham, A. W., Khan, O. F., Ling, J., Anderson, D. G., et al. (2017). An RNA nanoparticle vaccine against Zika virus elicits antibody and CD8+ T cell responses in a mouse model. Sci. Rep. 7:252. doi:10.1038/s41598-017-00193-w

Chan, J. F., Choi, G. K., Yip, C. C., Cheng, V. C., and Yuen, K. Y. (2016). Zika fever and congenital Zika syndrome: an unexpected emerging arboviral disease. J. Infect. 72, 507-524. doi: 10.1016/j.jinf.2016.02.011

Chan, J. F., To, K. K., Chen, H., and Yuen, K. Y. (2015). Cross-species transmission and emergence of novel viruses from birds. Curr. Opin. Virol. 10, 63-69. doi: 10.1016/j.coviro.2015.01.006

Chandramohan, B., Murugan, K., Panneerselvam, C., Madhiyazhagan, P., Chandirasekar, R., Dinesh, D., et al. (2016). Characterization and mosquitocidal potential of neem cake-synthesized silver nanoparticles: genotoxicity and impact on predation efficiency of mosquito natural enemies. Parasitol Res. 115, 1015-1025. doi: 10.1007/s00436-015-4829-9

Chang, C., Ortiz, K., Ansari, A., and Gershwin, M. E. (2016). The Zika outbreak of the 21st century. J. Autoimmun. 68, 1-13. doi: 10.1016/j.jaut.2016.02.006

Chang, K. S., Kim, G. H., Ha, Y. R., Jeong, E. K., Kim, H. C., Klein, T. A., et al. (2017). Monitoring and control of Aedes albopictus, a vector of Zika virus, near residences of imported Zika virus patients during 2016 in South Korea. Am. J. Trop. Med. Hyg. 98, 166-172. doi: 10.4269/ajtmh.17-0587

Chen, L. H., and Hamer, D. H. (2016). Zika virus: rapid spread in the western hemisphere. Ann. Intern. Med. 164, 613-615. doi: 10.7326/M16-0150 
Cheng, G., Cox, J., Wang, P., Krishnan, M. N., Dai, J., Qian, F., et al. (2010). A C-type lectin collaborates with a CD45 phosphatase homolog to facilitate West Nile virus infection of mosquitoes. Cell 142, 714-725. doi: 10.1016/j.cell.2010.07.038

Chitti, S. V., Prasad, A. K., and Saxena, S. K. (2016). Emerging Zika virus disease: a public health emergency of global concern. Virus Dis. 27, 211-214. doi: 10.1007/s13337-016-0317-9

Colpitts, T. M., Cox, J., Vanlandingham, D. L., Feitosa, F. M., Cheng, G., Kurscheid, S., et al. (2011). Alterations in the Aedes aegypti transcriptome during infection with West Nile, dengue and yellow fever viruses. PLoS Pathog. 7:e1002189. doi: 10.1371/journal.ppat.1002189

Coutinho-Abreu, I. V., and Ramalho-Ortigao, M. (2010). Transmission blocking vaccines to control insect-borne diseases: a review. Mem. Inst. Oswaldo Cruz. 105, 1-12. doi: 10.1590/S0074-02762010000100001

Cu, Y., Broderick, K. E., Banerjee, K., Hickman, J., Otten, G., Barnett, S., et al. (2013). Enhanced delivery and potency of self-amplifying mRNA Vaccines by electroporation in situ. Vaccines (Basel) 1, 367-383. doi: $10.3390 /$ vaccines 1030367

Cunha-Neto, E., Rosa, D. S., Harris, P. E., Olson, T., Morrow, A., Ciotlos, S., et al. (2017). An approach for a synthetic CTL vaccine design against Zika flavivirus using class I and class II epitopes identified by computer modeling. Front. Immunol. 8:640. doi: 10.3389/fimmu.2017.00640

D’Ortenzio, E., Matheron, S., de Lamballerie, X., Hubert, B., Piorkowski, G., Maquart, M., et al. (2016). Evidence of sexual transmission of Zika virus. $N$. Engl. J. Med. 374, 2195-2198. doi: 10.1056/NEJMc1604449

Darbro, J. M., and Thomas, M. B. (2009). Spore persistence and likelihood of aeroallergenicity of entomopathogenic fungi used for mosquito control. Am. J. Trop. Med. Hyg. 80, 992-997. doi: 10.4269/ajtmh.2009.80.992

Dasti, J. I. (2016). Zika virus infections: an overview of current scenario. Asian Pacific J. Trop. Med. 9, 621-625. doi: 10.1016/j.apjtm.2016.05.010

Dhalia, R., Maciel M. Jr., Cruz, F. S., Viana, I. F., Palma, M. L., August, T., et al. (2009). Membrane and envelope virus proteins co-expressed as lysosome associated membrane protein (LAMP) fused antigens: a potential tool to develop DNA vaccines a potential tool to develop DNA vaccines against flaviviruses. Anais da Academia Brasileira de Ciências 81, 663-669. doi: 10.1590/S0001-37652009000400005

Dhama, K., Tiwari, R., Chakraborty, S., Kumar, A., Karikalan, M., Singh, R., et al. (2013). Global warming and emerging infectious diseases of animals and humans: current scenario, challenges, solutions and future perspectives - a review. Int. J. Curr. Res. 5, 1942-1958.

Dhiman, R. C., Pahwa, S., Dhillon, G. P., and Dash, A. P. (2010). Climate change and threat of vector-borne diseases in India: are we prepared? Parasitol Res. 106, 763-773. doi: 10.1007/s00436-010-1767-4

Diagne, C. T., Diallo, D., Faye, O., Ba, Y., Faye, O., Gaye, A., et al. (2015). Potential of selected Senegalese Aedes spp. mosquitoes (Diptera: Culicidae) to transmit Zika virus. BMC Infect. Dis. 15:492. doi: 10.1186/s12879-015-1231-2

Diallo, D., Sall, A. A., Diagne, C. T., Faye, O., Faye, O., Ba, Y., et al. (2014). Zika virus emergence in mosquitoes in southeastern Senegal, 2011. PLoS ONE 9:e109442. doi: 10.1371/journal.pone.0109442

Dinglasan, R. R., and Jacobs-Lorena, M. (2008). Flipping the paradigm on malaria transmission-blocking vaccines. Trends Parasitol. 24, 364-370. doi: 10.1016/j.pt.2008.05.002

Dos Santos Franco, L., Oliveira Vidal, P., and Amorim, J. H. (2017). In silico design of a Zika virus non-structural protein 5 aiming vaccine protection against Zika and dengue in different human populations. J. Biomed. Sci. 24:88. doi: 10.1186/s12929-017-0395-Z

Dowd, K. A., DeMaso, C. R., Pelc, R. S., Speer, S. D., Smith, A. R., Goo, L., et al. (2016a). Broadly neutralizing activity of Zika virus-immune sera identifies a single viral serotype. Cell Rep. 16, 1485-1491. doi: 10.1016/j.celrep. 2016.07.049

Dowd, K. A., Ko, S. Y., Morabito, K. M., Yang, E. S., Pelc, R. S., DeMaso, C. R., et al. (2016b). Rapid development of a DNA vaccine for Zika virus. Science 354, 237-240. doi: 10.1126/science.aai9137

Dupont-Rouzeyrole, M., Biron, A., O’Connor, O., Huguon, E., and Descloux, E. (2016). Infectious Zika viral particles in breast milk. The Lancet 387:1051. doi: 10.1016/S0140-6736(16)00624-3

Dutra, H. L., dos Santos, L. M., Caragata, E. P., , Silva, J. B., , Villela, D. A., Macielde-Freitas, R., et al. (2015). From lab to field: the influence of urban landscapes on the invasive potential of Wolbachia in Brazilian Aedes aegypti mosquitoes. PLoS Negl. Trop. Dis. 9:e0003689. doi: 10.1371/journal.pntd.0003689

Dyer, O. (2016). Trials of Zika vaccine are set to begin in North America. BMJ 353:i3588. doi: 10.1136/bmj.i3588

Farcet, M. R., and Kreil, T. R. (2017). Zika virus is not thermostable: very effective virus inactivation during heat treatment (pasteurization) of human serum albumin. Transfusion 57, 797-801. doi: 10.1111/trf.13953

Favia, G., Ricci, I., Marzorati, M., Negri, I., Alma, A., Sacchi, L., et al. (2008). Bacteria of the genus Asaia: a potential paratransgenic weapon against malaria. Adv. Exp. Med. Biol. 627, 49-59. doi: 10.1007/978-0-387-78225-6_4

Fernandez, E., and Diamond, M. S. (2017). Vaccination strategies against Zika virus. Curr. Opin. Virol. 23, 59-67. doi: 10.1016/j.coviro.2017.03.006

Fotin-Mleczek, M., Duchardt, K. M., Lorenz, C., Pfeiffer, R., Ojkić-Zrna, S., Probst, J., et al. (2011). Messenger RNA-based vaccines with dual activity induce balanced TLR-7 dependent adaptive immune responses and provide antitumor activity. J. Immunother. 34, 1-15. doi: 10.1097/CJI.0b013e3181f7dbe8

Foy, B. D., Kobylinski, K. C., Chilson Foy, J. L., Blitvich, B. J., Travassos da Rosa, A., Haddow, A. D., et al. (2011). Probable non-vector-borne transmission of Zika virus, Colorado, USA. Emerging Infect. Dis.. 17, 880-882. doi: 10.3201/eid1705.101939

Gasperi, G., Bellini, R., Malacrida, A. R., Crisanti, A., Dottori, M., and Aksoy, S. (2012). A new threat looming over the Mediterranean basin: emergence of viral diseases transmitted by Aedes albopictus mosquitoes. PLoS Negl. Trop. Dis. 6:e1836. doi: 10.1371/journal.pntd.0001836

Gaudinski, M. R., Houser, K. V., Morabito, K. M., Hu, Z., Yamshchikov, G., Rothwell, R. S., et al. (2017). Safety, tolerability, and immunogenicity of two Zika virus DNA vaccine candidates in healthy adults: randomised, openlabel, phase 1 clinical trials. Lancet. doi: 10.1016/S0140-6736(17)33105-7. [Epub ahead of print].

Gautret, P., and Simon, F. (2016). Dengue, chikungunya and Zika and mass gatherings: what happened in Brazil, 2014. Travel Med. Infect. Dis. 14, 7-8. doi: 10.1016/j.tmaid.2015.12.004

Ghosh, A., Mandal, S., Bhattacharjee, I., and Chandra, G. (2005). Biological control of vector mosquitoes by some common exotic fish predators. Turk J. Biol. 29, $167-171$.

Goldberg, L. J., and Margalit, J. (1977). Bacterial spore demonstrating rapid larvicidal activity against Anopheles sergentii, Uranotaenia unguiculata, Culex univitattus, Aedes aegypti and Culex pipiens. Mosq. News 37, 355-358.

Goodsell, J. F., and Kats, L. B. (1999). Effect of introduced mosquitofish on Pacific Tree frogs and the role of alternative prey. Conserv. Biol. 13, 921-924. doi: 10.1046/j.1523-1739.1999.98237.x

Govindarajan, M., and Benelli, G. (2016). Eco-friendly larvicides from Indian plants: effectiveness of lavandulyl acetate and bicyclogermacrene on malaria, dengue and Japanese encephalitis mosquito vectors. Ecotoxicol. Environ. Saf. 133, 395-402. doi: 10.1016/j.ecoenv.2016.07.035

Govindarajan, M., Hoti, S. L., and Benelli, G. (2016b). Facile fabrication of ecofriendly nano-mosquitocides: biophysical characterization and effectiveness on neglected tropical mosquito vectors. Enzyme Microb. Technol. 95, 155-163. doi: 10.1016/j.enzmictec.2016.05.005

Govindarajan, M., Kadaikunnan, S., Alharbi, N. S., and Benelli, G. (2016a). Acute toxicity and repellent activity of the Origanum scabrum Boiss. \& Heldr. (Lamiaceae) essential oil against four mosquito vectors of public health importance and its biosafety on non-target aquatic organisms. Environ. Sci. Pollut. Res. Int. 23, 23228-23238. doi: 10.1007/s11356-016-7568-2

Griffin, L. (2014). Laboratory evaluation of predation on mosquito larvae by Australian mangrove fish. J. Vector Ecol. 39, 197-203. doi: 10.1111/j.1948-7134.2014.12087.x

Grischott, F., Puhan, M., Hatz, C., and Schlagenhauf, P. (2016). Non-vector-borne transmission of Zika virus: a systematic review. Travel Med. Infect. Dis. 14, 313-330. doi: 10.1016/j.tmaid.2016.07.002

Gulland, A. (2016). Zika virus is a global public health emergency, declares WHO. BMJ 352:i657. doi: 10.1136/bmj.i657.

Gupta, S., and Banerjee, S. (2013). Comparative assessment of mosquito biocontrol efficiency between guppy (Poecilia reticulata) and Panchax minnow (Aplocheilus panchax). Biosci. Disc. 4, 89-95.

Hajra, A., Bandyopadhyay, D., and Hajra, S. K. (2016). Zika virus: a global threat to humanity: a comprehensive review and current developments. N. Am. J. Med. Sci. 8, 123-128. doi: 10.4103/1947-2714.179112 
Harris, A. F., McKemey, A. R., Nimmo, D., Curtis, Z., Black, I., Morgan, S. A., et al. (2012). Successful suppression of a field mosquito population by sustained release of engineered male mosquitoes. Nat. Biotechnol. 30, 828-830. doi: $10.1038 /$ nbt.2350

Hirano, M., Hatakoshi, M., Kawada, H., and Takimoto, Y. (1998). Pyriproxyfen and other juvenile hormone analogues. Rev. Toxicol. 2, 357-394.

Huits, R., De Smet, B., Ariën, K. K., Van Esbroeck, M., Bottieau, E., and Cnops, L. (2017). Zika virus in semen: a prospective cohort study of symptomatic travellers returning to Belgium. Bull World Health Organ. 95, 802-809. doi: 10.2471/BLT.17.181370

Isoe, J., Zamora, J., and Miesfeld, R. L. (2009). Molecular analysis of the Aedes aegypti carboxypeptidase gene family. Insect Biochem. Mol. Biol. 39, 68-73. doi: 10.1016/j.ibmb.2008.09.006

Jaber, S., Mercier, A., Knio, K., Brun, S., and Kambris, Z. (2016). Isolation of fungi from dead arthropods and identification of a new mosquito natural pathogen. Parasit. Vectors 9:491. doi: 10.1186/s13071-016-1763-3

Jiang, D. B., Sun, Y. J., Cheng, L. F., Zhang, G. F., Dong, C., Jin, B. Q., et al. (2015). Construction and evaluation of DNA vaccine encoding Hantavirus glycoprotein N-terminal fused with lysosome-associated membrane protein. Vaccine 33, 3367-3376. doi: 10.1016/j.vaccine.2015.05.007

Kalimuthu, K., Lin, S. M., Tseng, L. C., Murugan, K., and Hwang, J. S. (2014). Bio-efficacy potential of seaweed Gracilaria firma with copepod, Megacyclops formosanus for the control larvae of dengue vector Aedes aegypti. Hydrobiologia 741, 113-123. doi: 10.1007/s10750-013-1745-9

Kang, C., Keller, T. H., and Luo, D. (2017). Zika virus protease: an antiviral drug target. Trends Microbiol. 25, 797-808. doi: 10.1016/j.tim.2017.07.001

Kant, R., Haq, S., Srivastava, H. C., and Sharma, V. P. (2013). Review of the bioenvironmental methods for malaria control with special reference to the use of larvivorous fishes and composite fish culture in central Gujarat, India. India J. Vector Borne Dis. 50, 1-12.

Kaslow, D. C. (1997). Transmission-blocking vaccines: uses and current status of development. Int. J. Parasitol. 27, 183-189. doi: 10.1016/S0020-7519(96)00148-8.

Kay, B. H., Tuyet Hanh, T. T., Le, N. H., Quy, T. M., Nam, V. S., Hang, P. V., et al. (2010). Sustainability and cost of a community-based strategy against Aedes aegypti in northern and central Vietnam. Am. J. Trop. Med. Hyg. 82, 822-830. doi: 10.4269/ajtmh.2010.09-0503

Kennedy, R. B. (2016). Pushing forward with Zika vaccines. EBioMed. 13, 29-30. doi: 10.1016/j.ebiom.2016.10.016

Kim, E., Erdos, G., Huang, S., Kenniston, T., Falo, L. D. Jr, and Gambotto, A. (2016). Preventative vaccines for Zika virus outbreak: preliminary evaluation. EBioMed 13, 315-320. doi: 10.1016/j.ebiom.2016.09.028

Kline, M. W., and Schutze, G. E. (2016). What pediatricians and other clinicians should know about Zika virus. JAMA Pediatr. 170, 309-0310. doi: 10.1001/jamapediatrics.2016.0429

Kollars, T. M. (2016). Reducing the risk of Zika and other Arboviruses by rapidly eliminating Aedes albopictus larvae from tires using a spray formulation of Bacillus thuringiensis israelensis. IOSR J. Dental Medical Sci. 15, 104-107. doi: 10.9790/0853-150907104107

Krow-Lucal, E. R., Biggerstaff, B. J., and Staples, J. E. (2017). Estimated incubation period for Zika virus disease. Emerg. Infect. Dis. 23, 841-844. doi: 10.3201/eid2305.161715

Kühnel, D., Müller, S., Pichotta, A., Radomski, K. U., Volk, A., and Schmidt, T. (2017). Inactivation of Zika virus by solvent/detergent treatment of human plasma and other plasma-derived products and pasteurization of human serum albumin. Transfusion 57, 802-810. doi: 10.1111/trf.13964

Mahesh Kumar, P., Murugan, K., Kovendan, K., Panneerselvam, C., Prasanna Kumar, K., Amerasan, D., et al. (2012). Mosquitocidal activity of Solanum xanthocarpum fruit extract and copepod Mesocyclops thermocyclopoides for the control of dengue vector Aedes aegypti. Parasitol Res. 111, 609-618. doi: 10.1007/s00436-012-2876-Z

Kumar, P. M., Murugan, K., Madhiyazhagan, P., Kovendan, K., Amerasan, D., Chandramohan, B., et al. (2016). Biosynthesis, characterization and acute toxicity of Berberis tinctoria- fabricated silver nanoparticles against the Asian tiger mosquito, Aedes albopictus, and the mosquito predators Toxorhynchites splendens and Mesocyclops thermocyclopoides. Parasitol. Res. 115, 751-759. doi: $10.1007 /$ s00436-015-4799-y
Kumar, S., Mishra, M., Wahab, N., and Warikoo, R. (2014). Larvicidal, repellent, and irritant potential of the seed-derived essential oil of Apium graveolens against dengue vector, Aedes aegypti L. (Diptera: Culicidae). Front Public Health. 2, 1-6. doi: 10.3389/fpubh.2014.00147

Lacey, L. A. (2007). Bacillus thuringiensis serovariety israelensis and Bacillus sphaericus for mosquito control. J. Am. Mosquito Control Asso. 23, 133-163. doi: 10.2987/8756-971X(2007)23[133:BTSIAB]2.0.CO;2

Lambrechts, L., Ferguson, N., Harris, E., Holmes, E. C., McGraw, E. A., O’Neill, S. L., et al. (2015). Assessing the epidemiological effect of Wolbachia for dengue control. Lancet Infect. Dis. 15, 862-866. doi: 10.1016/s1473-3099(15)00091-2.

Larocca, R. A., Abbink, P., Peron, J. P., Zanotto, P. M., Iampietro, M. J., BadamchiZadeh, A., et al. (2016). Vaccine protection against Zika virus from Brazil. Nature 536, 474-478. doi: 10.1038/nature18952

Laughhunn, A., Santa Maria, F., Broult, J., Lanteri, M. C., Stassinopoulos, A., Musso, D., et al. (2017). Amustaline (S-303) treatment inactivates high levels of Zika virus in red blood cell components. Transfusion 57, 779-789. doi: $10.1111 /$ trf.13993

Lees, R. S., Gilles, J. R. L., Hendrichs, J., Vreysen, M. J. B., and Bourtzis, K. (2015). Back to the future: the sterile insect technique against mosquito disease vectors. Curr. Opin. Insect. Sci. 10, 156-162. doi: 10.1016/j.cois.2015.05.011

Li, Y., Leneghan, D. B., Miura, K., Nikolaeva, D., Brian, I. J., Dicks, M. D., et al. (2016). Enhancing immunogenicity and transmission-blocking activity of malaria vaccines by fusing Pfs25 to IMX313 multimerization technology. Sci. Rep. 6:18848. doi: 10.1038/srep18848

Liu, Y., Zhang, F., Liu, J., Xiao, X., Zhang, S., Qin, C., et al. (2014). Transmissionblocking antibodies against mosquito C-type lectins for dengue prevention. PLoS Pathog. 10:e1003931. doi: 10.1371/journal.ppat.1003931

Londono-Renteria, B., Troupin, A., and Colpitts, T. M. (2016). Arbovirosis and potential transmission blocking vaccines. Parasit. Vectors 9:516. doi: 10.1186/s13071-016-1802-0

Lu, Y. (2003). Lysosomal targeting and genetic/DNA vaccines development. Discov. Med. 3, 54-55.

Maciel-de-Freitas, R., Avendanho, F. C., Santos, R., Sylvestre, G., Araújo, S. C., Lima, J. B., et al. (2014). Undesirable consequences of insecticide resistance following Aedes aegypti control activities due to a dengue outbreak. PLoS ONE 9:e92424. doi: 10.1371/journal.pone.0092424

Maharajan, M. K., Ranjan, A., Chu, J. F., Foo, W. L., Chai, Z. X., Lau, E. Y., et al. (2016). Zika virus infection: current concerns and perspectives. Clin. Rev. Allergy Immunol. 51, 383-394. doi: 10.1007/s12016-016-8554-7

Malone, R., Homan, J., Callahan, M., Glasspool-Malone, J., Damodaran, L., Schneider Ade, B., et al. (2016). ZIKA: medical countermeasure development challenges. PLoS Negl. Trop. Dis. 10:e0004530. doi: 10.1371/journal.pntd.0004530

Mansuy, J. M., Dutertre, M., Mengelle, C., Fourcade, C., Marchou, B., Delobel, P., et al. (2016). Zika virus: high infectious viral load in semen, a new sexually transmitted pathogen? Lancet Infect. Dis. 16:405. doi: 10.1016/S1473-3099(16)00138-9

Marano, G., Pupella, S., Vaglio, S., Liumbruno, G. M., and Grazzini, G. (2016). Zika virus and the never-ending story of emerging pathogens and transfusion medicine. Blood Transfus. 14, 95-100. doi: 10.2450/2015.0066-15

Mathivanana, T., Govindarajana, M., Elumalai, K., Krishnappaa, K., and Ananthan, A. (2010). Mosquito larvicidal and phytochemical properties of Ervatamia coronaria Stapf. (Family: Apocynaceae). J. Vector Borne Dis. 47, 178-180.

Mead, P. S., Hills, S. L., and Brooks, J. T. (2017). Zika virus as a sexually transmitted pathogen. Curr. Opin. Infect. Dis. 31, 39-44. doi: 10.1097/QCO.0000000000000414

Mischke, C. C., Griffin, M. J., Greenway, T. E., and Wise, D. (2016). Effect of mosquitofish, Gambusia affinis, on channel catfish Ictalurus punctatus, production ponds. J. World Aquacult. Soc. 44, 288-292. doi: 10.1111/jwas.12015

Modjarrad, K., Lin, L., George, S. L., Stephenson, K. E., Eckels, K. H., De La Barrera, R. A., et al. (2017). Preliminary aggregate safety and immunogenicity results from three trials of a purified inactivated Zika virus vaccine candidate: phase 1, randomised, double-blind, placebo-controlled clinical trials. Lancet. doi: 10.1016/S0140-6736(17)33106-9. [Epub ahead of print].

Morabito, K. M., and Graham, B. S. (2017). Zika Virus Vaccine Development. J. Infect. Dis. 216, S957-S963. doi: 10.1093/infdis/jix464 
Mourya, D. T., Shil, P., Sapkal, G. N., and Yadav, P. D. (2016). Zika virus: Indian perspectives. Indian J. Med. Res. 143, 553-564. doi: 10.4103/0971-5916.187103.

Mulla, M. S., Darwazeh, H. A., Kennedy, R., and Dawson, D. M. (1986). Evaluation of new insect growth regulator against mosquitoes with notes on non-target organisms. J. Am. Mosq. Control Assoc. 2, 314-320.

Munjal, A., Khandia, R., Dhama, K., Sachan, S., Karthik, K., Tiwari, R., et al. (2017b). Advances in developing therapies to combat Zika virus: current knowledge and future perspectives. Front. Microbiol. 8:1469. doi: $10.3389 /$ fmicb.2017.01469

Munjal, A., Khandia, R., Tiwari, R., Chakraborty, S., Karthik, K., and Dhama, K. (2017a). Advances in designing and developing vaccines against Zika virus. Int. J. Pharmacol. 13, 667-676. doi: 10.3923/ijp.2017.667.676

Murugan, K., Benelli, G., Panneerselvam, C., Subramaniam, J., Jeyalalitha, T., Dinesh, D., et al. (2015a). Cymbopogon citratus-synthesized gold nanoparticles boost the predation efficiency of copepod Mesocyclops aspericornis against malaria and dengue mosquitoes. Exp. Parasitol. 153, 129-138. doi: 10.1016/j.exppara.2015.03.017

Murugan, K., Kalimuthu, K., Mahesh Kumar, P., Hwang, J. S., and Nicoletti, M. (2013). Larval and pupal toxicity effects of Plectranthus amboinicus, Bacillus sphaericus and predatory copepods for the control of the dengue vector, Aedes aegypti. Phytoparasitica 41, 307-316. doi: 10.1007/s12600-013-0291-3

Murugan, K., Priyanka, V., Dinesh, D., Madhiyazhagan, P., Panneerselvam, C., Subramaniam, J., et al. (2015b). Predation by Asian bullfrog tadpoles, Hoplobatrachus tigerinus, against the dengue vector, Aedes aegypti, in an aquatic environment treated with mosquitocidal nanoparticles. Parasitol. Res. 114, 3601-3610. doi: 10.1007/s00436-015-4582-0

Musso, D., Aubry, M., Broult, J., Stassinopoulos, A., and Green, J. (2017). Zika virus: new emergencies, potential for severe complications and prevention of transfusion-transmitted Zika fever in the context of co-circulation of arboviruses. Blood Transfusion 15, 272-273. doi: 10.2450/2016.0003-16

Musso, D., Nhan, T., Robin, E., Roche, C., Bierlaire, D., Zisou, K., et al. (2014). Potential for Zika virus transmission through blood transfusion demonstrated during an outbreak in French Polynesia, November 2013 to February 2014. Euro Surveill. 19:pii: 20761. doi: 10.2807/1560-7917.ES2014.19.14.20761

Musso, D., Roche, C., Robin, E., Nhan, T., Teissier, A., and Cao-Lormeau, V. M. (2015). Potential sexual transmission of Zika virus. Emerging Infect. Dis. 21, 359-361. doi: 10.3201/eid2102.141363

Nathiya, V., Saravana Bhavan, P., Murugan, K., Panneerselvam, C., Suresh, U., Vadivalagan, C., et al. (2015). Predatory ability of Mesocyclops aspericornis on the larvae of Culex quinquefasciatus under monocrotophos polluted condition. Int. J. Modn. Res. Revs. 3, 630-634.

Neelakanta, G., and Sultana, H. (2015). Transmission-blocking vaccines: focus on anti-vector vaccines against tick-borne diseases. Arch. Immunol. Ther. Exp. 63, 169-179. doi: 10.1007/s00005-014-0324-8

Nguyen, T. H., Nguyen H. L., Nguyen, T. Y., Vu, S. N., Tran, N. D., Le, T. N., et al. (2015). Field evaluation of the establishment potential of wmelpop Wolbachia in Australia and Vietnam for dengue control. Parasit. Vectors 8:563. doi: 10.1186/s13071-015-1174-x

Nicastri, E., Castilletti, C., Liuzzi, G., Iannetta, M., Capobianchi, M. R., and Ippolito, G. (2016). Persistent detection of Zika virus RNA in semen for six months after symptom onset in a traveller returning from Haiti to Italy, February 2016. Euro Surveill. 21:30314. doi: 10.2807/1560-7917.ES.2016.21.32.30314

Pardi, N., Hogan, M. J., Pelc, R. S., Muramatsu, H., Andersen, H., DeMaso, C. R., et al. (2017). Zika virus protection by a single low-dose nucleoside-modified mRNA vaccination. Nature 543, 248-251. doi: 10.1038/nature21428

Parham, P. E., Waldock, J., Christophides, G. K., and Michael, E. (2015). Climate change and vector-borne diseases of humans. Philos. Trans. R. Soc. Lond. B. Biol. Sci. 370:20140377. doi: 10.1098/rstb.2014.0377

Phuc, H. K., Andreasen, M. H., Burton, R. S., Vass, C., Epton, M. J., Pape, G., et al. (2007). Late-acting dominant lethal genetic systems and mosquito control. BMC Biol. 5:11. doi: 10.1186/1741-7007-5-11

Phukon, H. K., and Biswas, S. P. (2013). An investigation on larvicidal efficacy of some indigenous fish species of Assam, India. Adv. Biores. 4, 22-25.

Pierre, D. Y. S., Nchiwan, N. E., Okechukwu, E. C., and Lame, Y. (2014). Larvicidal and pupicidal toxicities of Plectranthus glandulosus and Callistemon rigidus leaf essential oils against three mosquito species. J. Mosquito Res. 4, 5-14. doi: $10.5376 / \mathrm{jmr} .2014 .04 .0002$
Prabhu, K., Murugan, K., Nareshkumar, A., Ramasubramanian, N., and Bragadeeswaran, S. (2011). Larvicidal and repellent potential of Moringa oleifera against malarial vector, Anopheles stephensi Liston (Insecta: Diptera: Culicidae). Asian Pac. J. Trop. Biomed. 1, 124-129. doi: 10.1016/S2221-1691(11)60009-9

Qian, F., Wu, Y., Muratova, O., Zhou, H., Dobrescu, G., Duggan, P., et al. (2007). Conjugating recombinant proteins to Pseudomonas aeruginosa ExoProtein A: a strategy for enhancing immunogenicity of malaria vaccine candidates. Vaccine 25, 3923-3933. doi: 10.1016/j.vaccine.2007.02.073

Ramkumar, G., and Karthi, S. (2015). Adulticidal and smoke toxicity of Cipadessa baccifera (Roth) plant extracts against Anopheles stephensi, Aedes aegypti, and Culex quinquefasciatus. Parasitol. Res. 114, 167-173. doi: 10.1007/s00436-014-4173-5

Ramkumar, G., Karthi, S., Muthusamy, R., Suganya, P., Natarajan, D., Kweka, E. J., et al. (2016). Mosquitocidal effect of Glycosmis pentaphylla leaf extracts against three mosquito species (Diptera: Culicidae). PLoS ONE 11:e0158088. doi: 10.1371/journal.pone. 0158088

Rather, I. A., Kumar, S., Bajpai, V. K., Lim, J., and Park, Y. H. (2017). Prevention and control strategies to counter Zika epidemic. Front. Microbiol. 8:305. doi: 10.3389/fmicb.2017.00305

Reegan, A. D., Gandhi, M. R., Paulraj, M. G., and Ignacimuthu, S. (2015). Ovicidal and oviposition deterrent activities of medicinal plant extracts against Aedes aegypti L. and Culex quinquefasciatus say mosquitoes (Diptera: Culicidae). Osong. Public Health Res. Perspect. 6, 64-69. doi: 10.1016/j.phrp.2014.08.009

Richards, S. L., Balanay, J. A. G., Harris, J. W., Banks, V. M., and Meshnick, S. (2017). Residual effectiveness of permethrin-treated clothing for prevention of mosquito bites under simulated conditions. J. Environ. Health 79, 8-15.

Richner, J. M., Himansu, S., Dowd, K. A., Butler, S. L., Salazar, V., Fox, J. M., et al. (2017). Modified mRNA vaccines protect against Zika virus infection. Cell, 1114-1125.e10. doi: 10.1016/j.cell.2017.02.017

Rodriguez, S. D., Chung, H. N., Gonzales, K. K., Vulcan, J., Li, Y., Ahumada, J. A., et al. (2017). Efficacy of some wearable devices compared with spray-on insect repellents for the yellow fever Mosquito, Aedes aegypti (L.) (Diptera: Culicidae). J. Insect Sci. 17:24. doi: 10.1093/jisesa/iew117

Rossi, P., Ricci, I., Cappelli, A., Damiani, C., Ulissi, U., Mancini, M. V., et al. (2015). Mutual exclusion of Asaia and Wolbachia in the reproductive organs of mosquito vectors. Parasit. Vectors 8:278. doi: 10.1186/s13071-015-0888-0

Sankar, S., Ramamurthy, M., Nandagopal, B., and Sridharan, G. (2017). In silico validation of D7 salivary protein-derived B-and T-cell epitopes of Aedes aegypti as potential vaccine to prevent transmission of flaviviruses and togaviruses to humans. Bioinformation 13, 366-375. doi: 10.6026/97320630013366

Santa Maria, F., Laughhunn, A., Lanteri, M. C., Aubry, M., Musso, D., and Stassinopoulos, A. (2017). Inactivation of Zika virus in platelet components using amotosalen and ultraviolet A illumination. Transfusion 57, 2016-2025. doi: $10.1111 /$ trf.14161

Sarwar, M. (2015). Control of dengue carrier Aedes mosquitoes (Diptera: Culicidae) larvae by larvivorous fishes and putting it into practice within water bodies. Int. J. Prev. Med. 1, 232-237.

Schaper, S., and Hernández-Chavarría, F. (2006). Scanning electron microscopy of damage caused by Mesocyclops thermocyclopoides (Copepoda: Cyclopoidea) on larvae of the Dengue fever vector Aedes aegypti (Diptera: Culicidae). Rev. Biol. Trop. 54, 843-846.

Shan, C., Muruato, A. E., Jagger, B. W., Richner, J., Nunes, B. T. D., Medeiros, D. B. A., et al. (2017b). A single-dose live-attenuated vaccine prevents Zika virus pregnancy transmission and testis damage. Nat. Commun. 8:676. doi: 10.1038/s41467-017-00737-8

Shan, C., Muruato, A. E., Nunes, B. T. D., Luo, H., Xie, X., Medeiros, D. B. A., et al. (2017a). A live-attenuated Zika virus vaccine candidate induces sterilizing immunity in mouse models. Nat. Med. 23, 763-767. doi: 10.1038/nm.4322

Sharma, A., and Lal, S. K. (2017). Zika virus: transmission, detection, control, and prevention. Front. Microbiol. 8:110. doi: 10.3389/fmicb.2017.00110

Sikka, V., Chattu, V. K., Popli, R. K., Galwankar, S. C., Kelkar, D., Sawicki, S. G., et al. (2016). The emergence of ZIKA as a global health security threat: a review and a consensus statement of the INDUSEM Joint working Group (JWG). J. Global Infect. Dis. 8, 3-15. doi: 10.4103/0974-777X.176140

Singh, R. K., Dhama, K., Karthik, K., Tiwari, R., Khandia, R., Munjal, A., et al. (2018). Advances in diagnosis, surveillance, and monitoring of Zika virus: an update. Front. Microbiol. 8:2677. doi: 10.3389/fmicb.2017.02677 
Singh, R. K., Dhama, K., Malik, Y. S., Ramakrishnan, M. A., Karthik, K., Tiwari, R., et al. (2016). Zika virus - emergence, evolution, pathology, diagnosis, and control: current global scenario and future perspectives - a comprehensive review. Vet. Quart. 36, 150-175. doi: 10.1080/01652176.2016.1188333

Singh, R. K., Dhama, K., Malik, Y. S., Ramakrishnan, M. A., Karthik, K., Tiwari, R., et al. (2017). Ebola virus - epidemiology, diagnosis and control: threat to humans, lessons learnt and preparedness plans - An update on its 40 year's journey. Vet. Quart. 37, 98-135. doi: 10.1080/01652176.2017.1309474

Sluydts, V., Durnez, L., Heng, S., Gryseels, C., Canier, L., Kim, S., et al. (2016). Efficacy of topical mosquito repellent (picaridin) plus long-lasting insecticidal nets versus long-lasting insecticidal nets alone for control of malaria: a cluster randomised controlled trial. Lancet Infect Dis. 16, 1169-1177. doi: 10.1016/S1473-3099(16)30148-7

Snetselaar, J., Andriessen, R., Suer, R. A., Osinga, A. J., Knols, B. G., and Farenhorst, M. (2014). Development and evaluation of a novel contamination device that targets multiple life-stages of Aedes aegypti. Parasit. Vectors 7:200. doi: 10.1186/1756-3305-7-200

Souza, T. M., Farias, D. F., Soares, B. M., Viana, M. P., Lima, G. P., Machado, L. K., et al. (2011). Toxicity of Brazilian plant seed extracts to two strains of Aedes aegypti (Diptera: Culicidae) and nontarget animals. J. Med. Entomol. 48, 846-851. doi: 10.1603/ME10205

Specter, M. (2012). The Mosquito Solution. The New Yorker. Available online at: http://www.newyorker.com/magazine/2012/07/09/the-mosquito-solution

Suarez, M. F., Marten, G. G., and Clark, G. G. (1992). A simple method for cultivating freshwater copepods used in biological control of Aedes aegypti. J. Am. Mosq. Control Assoc. 8, 409-412.

Sumathy, K., Kulkarni, B., Gondu, R. K., Ponnuru, S. K., Bonguram, N., Eligeti, R., et al. (2017). Protective efficacy of Zika vaccine in AG129 mouse model. Sci. Rep. 7:46375. doi: 10.1038/srep46375

Tennyson, S., Ravindran, K. J., and Arivoli, S. (2012). Screening of twenty five plant extracts for larvicidal activity against Culex quinquefasciatus Say (Diptera: Culicidae). Asian Pacific J. Trop. Biomed. 2, S1130-S1134. doi: 10.1016/S2221-1691(12)60372-4

Tham, H. W., Balasubramaniam, V. R., Tejo, B. A., Ahmad, H., and Hassan, S. S. (2014). CPB1 of Aedes aegypti interacts with DENV2 E protein and regulates intracellular viral accumulation and release from midgut cells. Viruses 6, 5028-5046. doi: 10.3390/v6125028

Tiago, P. V., de Oliveira, N. T., de Luna, E. Á., and Lima, A. (2014). Biological insect control using Metarhizium anisopliae: morphological, molecular, and ecological aspects. Cienc. Rural. 44, 645-651. doi: 10.1590/S0103-84782014000400012

Unlu, I., Suman, D. S., Wang, Y., Klingler, K., Faraji, A., and Gaugler, R. (2017). Effectiveness of autodissemination stations containing pyriproxyfen in reducing immature Aedes albopictus populations. Parasit. Vectors 10:139. doi: 10.1186/s13071-017-2034-7

Uragayala, S., Verma, V., Natarajan, E., Velamuri, P. S., and Kamaraju, R. (2015). Adulticidal \& larvicidal efficacy of three neonicotinoids against insecticide susceptible \& resistant mosquito strains. Indian J. Med. Res. 142, 64-70. doi: 10.4103/0971-5916.176624

Usman Mirza, M., Rafique, S., Ali, A., Munir, M., Ikram, N., Manan, A., et al. (2016). Towards peptide vaccines against Zika virus: immunoinformatics combined with molecular dynamics simulations to predict antigenic epitopes of Zika viral proteins. Sci. Rep. 6:37313. doi: 10.1038/srep37313

van den Berg, H., Zaim, M., Yadav, R. S., Soares, A. , Ameneshewa, B., and Mnzava, A. (2012). Global trends in the use of insecticides to control vector-borne diseases. Environ. Health Perspect. 120, 577-582. doi: 10.1289/ehp.1104340

Vasquez, A. M., Sapiano, M. R., Basavaraju, S. V., Kuehnert, M. J., and RiveraGarcia, B. (2016). Survey of Blood Collection Centers and Implementation of Guidance for Prevention of Transfusion-Transmitted Zika Virus Infection Puerto Rico, 2016. Am. J. Transpl. 16, 2487-2490. doi: 10.1111/ajt.13941

Veljkovic, V., and Paessler, S. (2016). Possible repurposing of seasonal influenza vaccine for prevention of Zika virus infection. F1000 Res. 5:190. doi: 10.12688/f1000research.8102.2

Vest, K. G. (2017). Zika virus update: more on an emerging arboviral disease in the western hemisphere. Disaster Med. Public Health Prep. 11, 163-167. doi: $10.1017 / \mathrm{dmp} .2016 .105$ von Seidlein, L., Kekul,é, A. S., and Strickman, D. (2017). Novel vector control approaches: the future for prevention of Zika virus transmission? PLoS Med. 14:e1002219. doi: 10.1371/journal.pmed.1002219

Vu, S. N., Nguyen, T. Y., Tran, V. P., Truong, U. N., Le, Q. M., Le, V. L., et al. (2005). Elimination of dengue by community programs using Mesocyclops (Copepoda) against Aedes aegypti in central Vietnam. Am. J. Trop. Med. Hyg. 72, 67-73. doi: 10.4269/ajtmh.2005.72.67

Vythilingam, I., Sam, J. I. C., Chan, Y. F., Khaw, L. T., and Wan Sulaiman, W. Y. (2016). New paradigms for virus detection, surveillance and control of Zika virus vectors in the settings of southeast asia. Front. Microbiol. 7:1452. doi: $10.3389 /$ fmicb. 2016.01452

Walker, T., Johnson, P., Moreira, L. A., Iturbe-Ormaetxe, I., Frentiu, F. D., McMeniman, C. J., et al. (2011). The wMel Wolbachia strain blocks dengue and invades caged Aedes aegypti populations. Nature 476, 450-453. doi: $10.1038 /$ nature10355

Walton, W. E., Henke, J. A., and Why, A. M. (2012). "Gambusia affinis (Baird and Girard) and Gambusia holbrooki Girard (Mosquitofish)," in A Handbook of Global Freshwater Invasive Species. ed R. A. Francis (London: Earthscan), 261-273.

Weaver, S. (2013). Urbanization and geographic expansion of zoonotic arboviral diseases: mechanisms and potential strategies for prevention. Trends Microbiol. 21, 360-363. doi: 10.1016/j.tim.2013.03.003

Weaver, S. C., Costa, F., Garcia-Blanco, M. A., Ko, A. I., Ribeiro, G. S., Saade, G., et al. (2016). Zika virus: History, emergence, biology, and prospects for control. Antiviral Res. 130, 69-80. doi: 10.1016/j.antiviral.2016.03.010

Werren, J. H. (1997). Biology of Wolbachia. Annu. Rev. Entomol. 42, 587-609. doi: 10.1146/annurev.ento.42.1.587

Weterings, R. (2015). Tadpoles of three common anuran species from Thailand do not prey on mosquito larvae. J. Vectors Ecol. 40, 230-232. doi: $10.1111 /$ jvec. 12158

Whitehead, S. S., Woodson, S. E., Durbin, A. P., Pletnev, A. G., and Tsetsarkin, K. A. (2017). Live Attenuated Zika Virus Vaccine. WO2017156511A1.

Whyard, S., Erdelyan, C. N., Partridge, A. L., Singh, A. D., Beebe, N. W., and Capina, R. (2015). Silencing the buzz: a new approach to population suppression of mosquitoes by feeding larvae double-stranded RNAs. Parasit. Vectors. 8:96. doi: 10.1186/s13071-015-0716-6

Wilson, F. (1960). "A review of the biological control of insects and Weeds in Australia and Australian New Guinea, 1," in Commonwealth Institute of Biological Control Technical Communication (Ottawa, ON), 80-91.

World Health Organization (1997). Chemical Methods for the Control of Vector and Pests of Public Health Importance. Geneva: WHO/CTD/WHOPES/97.2.

Zanluca, C., and dos Santos, C. N. D. (2016). Zika virus- an overview. Microb. Infect. 18, 295-301. doi: 10.1016/j.micinf.2016.03.003

Zhang, Q., Sun, K., Chinazzi, M., Pastore, Y., Piontti, A., Dean, N. E., et al. (2017). Spread of Zika virus in the Americas. Proc. Natl. Acad. Sci. U.S.A. 114, E4334-E4343. doi: 10.1073/pnas.1620161114

Zhao, H., Fernandez, E., Dowd, K. A., Speer, S. D., Platt, D. J., Gorman, M. J., et al. (2016). Structural basis of Zika virus-specific antibody protection. Cell 166, 1016-1027. doi: 10.1016/j.cell.2016. 07.020

Zuharah, W. F., Fadzly, N., Yusof, N. A., and Dieng, H. (2015). Risky behaviors: effects of Toxorhynchites splendens (Diptera: Culicidae) predator on the behavior of three mosquito species. J. Insect Sci. 15:128. doi: $10.1093 /$ jisesa/iev115

Conflict of Interest Statement: The authors declare that the research was conducted in the absence of any commercial or financial relationships that could be construed as a potential conflict of interest.

Copyright (c) 2018 Singh, Dhama, Khandia, Munjal, Karthik, Tiwari, Chakraborty, Malik and Bueno-Mari. This is an open-access article distributed under the terms of the Creative Commons Attribution License (CC BY). The use, distribution or reproduction in other forums is permitted, provided the original author(s) and the copyright owner are credited and that the original publication in this journal is cited, in accordance with accepted academic practice. No use, distribution or reproduction is permitted which does not comply with these terms. 